\title{
The Pharmacological Activities of Crocus sativus L.: A Review Based on the Mechanisms and Therapeutic Opportunities of its Phytoconstituents
}

\author{
Monica Butnariu $\mathbb{D}^{1},{ }^{1}$ Cristina Quispe, ${ }^{2}$ Jesús Herrera-Bravo $\mathbb{D},{ }^{3,4}$ Javad Sharifi-Rad $\mathbb{D},{ }^{5}$ \\ Laxman Singh, ${ }^{6}$ Nora M. Aborehab, ${ }^{7}$ Abdelhakim Bouyahya $\mathbb{D}^{8},{ }^{8}$ Alessandro Venditti $\mathbb{D},{ }^{9}$ \\ Surjit Sen, ${ }^{10,11}$ Krishnendu Acharya, ${ }^{10}$ Moein Bashiry, ${ }^{12}$ Shahira M. Ezzat $\mathbb{D},{ }^{13,14}$ \\ William N. Setzer, ${ }^{15}$ Miquel Martorell ${ }^{10},{ }^{16}$ Ksenija S. Mileski, ${ }^{17}$ Iulia-Cristina Bagiu, ${ }^{18,19}$ \\ Anca Oana Docea, ${ }^{20}$ Daniela Calina $\left(\mathbb{D},{ }^{21}\right.$ and William C. Cho $\mathbb{D D}^{22}$ \\ ${ }^{1}$ Banat's University of Agricultural Sciences and Veterinary Medicine "King Michael I of Romania" from Timisoara, \\ Timișoara, Romania \\ ${ }^{2}$ Facultad de Ciencias de la Salud, Universidad Arturo Prat, Avda Arturo Prat 2120, Iquique 1110939, Chile \\ ${ }^{3}$ Departamento de Ciencias Básicas, Facultad de Ciencias, Universidad Santo Tomas, Chile \\ ${ }^{4}$ Center of Molecular Biology and Pharmacogenetics, Scientific and Technological Bioresource Nucleus, Universidad de La Frontera, \\ Temuco 4811230, Chile \\ ${ }^{5}$ Facultad de Medicina, Universidad del Azuay, Cuenca, Ecuador \\ ${ }^{6}$ G.B. Pant National Institute of Himalayan Environment \& Sustainable Development Kosi-Katarmal, Almora, Uttarakhand, India \\ ${ }^{7}$ Biochemistry Department, Faculty of Pharmacy, October University for Modern Sciences and Arts (MSA), \\ 6th of October 12566, Egypt \\ ${ }^{8}$ Laboratory of Human Pathologies Biology, Department of Biology, Faculty of Sciences and Genomic Center of Human Pathologies, \\ Faculty of Medicine and Pharmacy, Mohammed V University of Rabat, Morocco \\ ${ }^{9}$ Dipartimento di Chimica, "Sapienza" Università di Roma, Piazzale Aldo Moro 5, 00185 Rome, Italy \\ ${ }^{10}$ Molecular and Applied Mycology and Plant Pathology Laboratory, Department of Botany, University of Calcutta, \\ Kolkata 700019, India \\ ${ }^{11}$ Department of Botany, Fakir Chand College, Diamond Harbour, West Bengal 743331, India \\ ${ }^{12}$ Department of Food Science and Technology, Nutrition and Food Sciences Faculty, Kermanshah University of Medical Sciences, \\ Kermanshah, Iran \\ ${ }^{13}$ Pharmacognosy Department, Faculty of Pharmacy, Cairo University, Kasr El-Ainy Street, Cairo 11562, Egypt \\ ${ }^{14}$ Pharmacognosy Department, Faculty of Pharmacy, October University for Modern Sciences and Arts (MSA), \\ 6th of October 12566, Egypt \\ ${ }^{15}$ Department of Chemistry, University of Alabama in Huntsville, Huntsville, AL 35899, USA \\ ${ }^{16}$ Department of Nutrition and Dietetics, Faculty of Pharmacy, University of Concepcion, Concepcion, Chile \\ ${ }^{17}$ Department of Morphology and Systematic of Plants, Faculty of Biology, University of Belgrade, Studentski Trg 16, \\ 11000 Belgrade, Serbia \\ ${ }^{18}$ Victor Babes University of Medicine and Pharmacy of Timisoara Discipline of Microbiology, Timișoara, Romania \\ ${ }^{19}$ Multidisciplinary Research Center on Antimicrobial Resistance, Timișoara, Romania \\ ${ }^{20}$ Department of Toxicology, University of Medicine and Pharmacy of Craiova, 200349 Craiova, Romania \\ ${ }^{21}$ Department of Clinical Pharmacy, University of Medicine and Pharmacy of Craiova, 200349 Craiova, Romania \\ ${ }^{22}$ Department of Clinical Oncology, Queen Elizabeth Hospital, Kowloon, Hong Kong
}

Correspondence should be addressed to Javad Sharifi-Rad; javad.sharifirad@gmail.com,

Miquel Martorell; martorellpons@gmail.com, Daniela Calina; calinadaniela@gmail.com, and William C. Cho; chocs@ha.org.hk

Received 19 May 2021; Revised 22 January 2022; Accepted 28 January 2022; Published 14 February 2022

Academic Editor: Amit Kumar Nayak 
Copyright (c) 2022 Monica Butnariu et al. This is an open access article distributed under the Creative Commons Attribution License, which permits unrestricted use, distribution, and reproduction in any medium, provided the original work is properly cited.

\begin{abstract}
Crocus species are mainly distributed in North Africa, Southern and Central Europe, and Western Asia, used in gardens and parks as ornamental plants, while Crocus sativus L. (saffron) is the only species that is cultivated for edible purpose. The use of saffron is very ancient; besides the use as a spice, saffron has long been known also for its medical and coloring qualities. Due to its distinctive flavor and color, it is used as a spice, which imparts food preservative activity owing to its antimicrobial and antioxidant activity. This updated review discusses the biological properties of Crocus sativus L. and its phytoconstituents, their pharmacological activities, signaling pathways, and molecular targets, therefore highlighting it as a potential herbal medicine. Clinical studies regarding its pharmacologic potential in clinical therapeutics and toxicity studies were also reviewed. For this updated review, a search was performed in the PubMed, Science, and Google Scholar databases using keywords related to Crocus sativus L. and the biological properties of its phytoconstituents. From this search, only the relevant works were selected. The phytochemistry of the most important bioactive compounds in Crocus sativus L. such as crocin, crocetin, picrocrocin, and safranal and also dozens of other compounds was studied and identified by various physicochemical methods. Isolated compounds and various extracts have proven their pharmacological efficacy at the molecular level and signaling pathways both in vitro and in vivo. In addition, toxicity studies and clinical trials were analyzed. The research results highlighted the various pharmacological potentials such as antimicrobial, antioxidant, cytotoxic, cardioprotective, neuroprotective, antidepressant, hypolipidemic, and antihyperglycemic properties and protector of retinal lesions. Due to its antioxidant and antimicrobial properties, saffron has proven effective as a natural food preservative. Starting from the traditional uses for the treatment of several diseases, the bioactive compounds of Crocus sativus L. have proven their effectiveness in modern pharmacological research. However, pharmacological studies are needed in the future to identify new mechanisms of action, pharmacokinetic studies, new pharmaceutical formulations for target transport, and possible interaction with allopathic drugs.
\end{abstract}

\section{Introduction}

The genus Crocus is a member of the Iridaceae (subfamily Crocoideae) and consists of about 100 species that occur in the wild. These are mainly found in central-southern Europe (Balkan Peninsula), North Africa, and Western Asia [1]. Several species of this genus are currently used in gardens and parks as ornamental plants for their colorful flowers, while Crocus sativus $\mathrm{L}$. (saffron) is the only species that is cultivated for the edible purpose [2]. The use of saffron is very ancient: its earliest representation appeared approximately 4000 years ago in some paintings and ceramics of the Minoan civilization in the region of Crete $[3,4]$. The stigmas from flowers are traditionally handpicked at dawn to preserve all the aroma and organoleptic characteristics. Then the stigmas are dried in the shade and finally powdered [5]. Due to its distinctive flavor and yellow-orange color, it has an ancient use as spice in Arab, European, Indian, and Persian cuisine. It is also used in liquors, candies, food supplements $[5,6]$, and medical and coloring qualities [7-9].

Among the phytoconstituents, there have been described several compounds that are thought to be the chemical determinants of the bitterness, scent, and color of saffron [10]. These are formally terpenoids or thought to be derived from terpenoid precursors. In particular, these are the apocarotenoids such as trans-crocetin and its glycosylated forms (crocins), especially trans-crocetin $\operatorname{di}-(\beta$-D-gentiobiosyl) ester and trans-crocetin ( $\beta$-D-gentiobiosyl)-( $\beta$-D-glucosyl) ester, together with picrocrocin and safranal (Figure 1), formerly a monoterpene glycoside and a monoterpene, respectively, and believed to be degradation products of zeaxanthin. As minor components, which also contribute to the spice color and biological effects, there are a series of glycosidic derivatives of kaempferol (Figure 1) [11] and quercetin [12]. Other minor components that contribute to the peculiar aroma of saffron are volatile compounds related to isophorone $[13,14]$.

Obviously, several of the medicinal and healthpromoting properties attributed to saffron are due to the presence of these compounds. For example, safranal, in addition to its antioxidant and radical-scavenger properties, is useful as an anticonvulsant and antidepressant in preclinical models [15-18]. Due to the high added value of saffron as a spice and of its chemical constituents mainly related to the healthy properties, the studies on saffron and its plant source (C. sativus) are in the limelight, especially concerning the analytical methods used to evaluate the quality and to identify marker compounds related to the country of origin.

In this updated review, the following aspects of Crocus plants are considered: traditional uses, phytochemical composition, pharmacological properties with mechanisms evidenced from in vitro and in vivo studies, clinical studies, toxicological data, and upcoming clinical perspectives.

\section{Methodology}

An extensive search of the PubMed, Science, and Google Scholar databases was conducted to select the most important information for this updated review. The main search keywords were: "Crocus plant," "Crocus sativus," "ethnopharmacology," "phytoconstituents," "chemical compounds," "pharmacological activity," "pharmacological mechanisms," "human clinical studies," "toxicity," and "food preservatives."

Inclusion criteria are as follows: only extenso articles written in English that included data on Crocus sativus L. analyzed, chemical compounds isolated from each genus, pharmacological molecular research for each of the studied plants, types of in vitro/in vivo pharmacological studies, concentration and dose at which the chemical compounds 


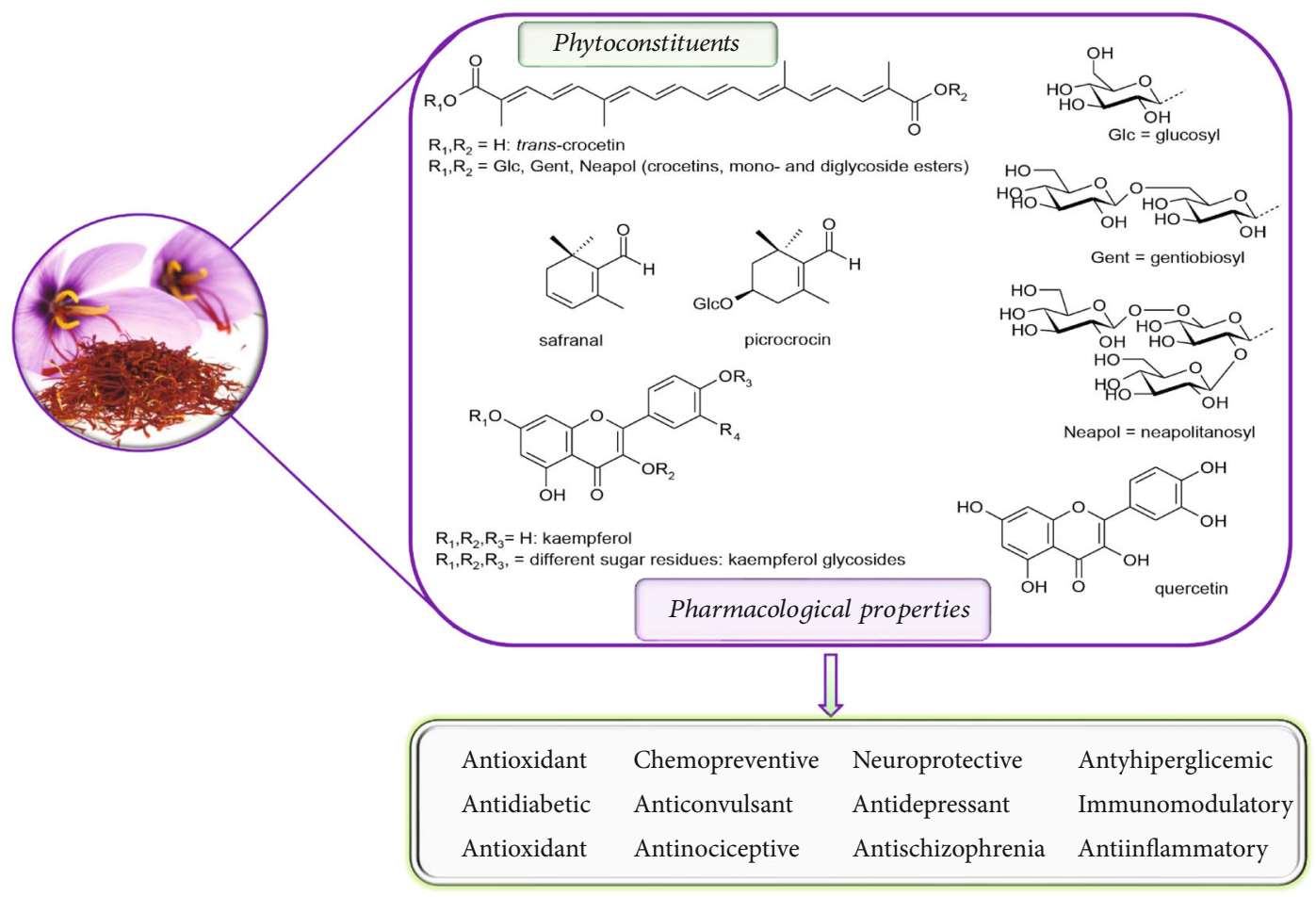

Figure 1: The main phytoconstituents of Crocus sativus L. and their pharmacological properties.

studied were pharmacologically active, clinical trials, and toxicological data. The chemical names were validated with PubChem and SciFinder, and the plant names were in accordance with The Plant List $[19,20]$. The most important data have been summarized in the tables and figures presented in this article.

Exclusion criteria are as follows: abstracts, letters to the editor, papers in languages other than English, studies that did not have dose-effect correlations, studies that did not have proven pharmacological activity, and studies that included homeopathic preparations.

\section{Traditional Medicine Use of Crocus Plants}

The folklore knowledge and extensive traditional use of medicinal Crocus sativus L. have a long history worldwide $[21,22]$. The cultivation of Crocus species for culinary and therapeutic purposes has been known from ancient times, first taking place in Greece and Iran. Later, the utilization of these plants was spread through the Mediterranean region to Eastern Europe and South Asia and China [1]. Although C. sativus was the most popular medicinal plant in European and Asian countries for ages, among medically significant herbs from this genus are also Crocus caspius Fisch. \& C.A.Mey. ex Hohen, Crocus heuffelianus Herb., Crocus hyemalis Boiss. \& Blanche, and Crocus vernus (L.) Hill. Their ethnobotanical importance is reflected through traditional use against various ailments and health disorders [23-27].

The traditional application of $C$. sativus is very diverse from diet and cosmetics to essential roles in medicine. It is a reputable plant owing to the specific aroma, flavor, and color of the stiles. As a valuable medicinal plant, it is a part of many alternative therapies and folklore medicines [4, 22]. It is documented that saffron was applied for the treatment of about 90 health disorders by different cultures [28].

In some Asian countries, traditional knowledge on saffron healing effects dates from prehistoric periods [8, 29]. The first records about its medical application date from the 12 th century BC [30]. Saffron was recognized by different nations in the Middle East and South Asia as a healthpromoting drug and medicine to fight various diseases. It is believed that the people of ancient Persia were the first to cultivate this species for their traditional needs. In Persian traditional medicine, saffron was used as a tonic for the strength and meaning of the organism, especially the vascular and nervous system (NS). Additionally, it is an ingredient of recipes for the treatment of depression, insomnia, measles, and dysentery [8]. Concerning this, C. sativus remains one of the most important medicinal drugs in traditional Iranian medicine $[4,30]$.

It was an important curative herb in ancient Greece, Rome, and Egypt, South and Central Asia (Unani), Hindu (Ayurveda), and Chinese medicine [21, 31, 32]. Also, C. sativus has been utilized as a medicinal spice by the Moroccan people [30] and some locals in Jordan [23].

The ancient Romans added this plant to wines to prevent hangovers and intoxication. Also, it was used in ancient Egypt and Greece as a herbal remedy to fight ulcers on the skin or mucous membranes to reduce eye health problems such as pain, infection, or cataracts and to heal some urinary and menstrual disorders [30]. In Unani medicine, this spice is also recognized as a remedy for urinary and kidney infections, and it is used as a part of the mixtures against menstrual disorders. Besides, it is 
considered stomachic, while in combination with honey, it is useful as a diuretic [31].

In Ayurveda medicine, saffron has many purposes as well. It is recommended against skin problems, asthma, arthritis, and kidney and digestive disorders. In powdered form, the herb is useful for external application on wounds, swellings, or major bleedings [30]. Powdered saffron is also advised for the treatment of poor vision, cataracts, and blindness [8]. This herb acts against diabetes when combined with ghee. Among its most famous roles in Ayurveda, the system is in the reduction of the enlargement of the spleen and the liver. [21, 28, 31].

In general, C. sativus is advised as a strengthening tonic that stimulates the immune defense, and it is a common ingredient of restorative preparations recommended for the general improvement of the physical and mental health of the body [30]. As an antiseptic and anti-inflammatory drug, it heals bacterial and fungal infections, inflammations, insect bites, and also apoplexy, alcoholism, arthritis, and diabetes [30].

Saffron's stigmas are extensively applied as an indigenous medicine across India. It serves as an antiseptic, analgesic, and expectorant agent as a nerve sedative and stimulator for immunity, blood flow, and menstruation. Also, it is effective against smallpox and a wide range of stomach problems. In lower doses, this spice can stimulate the contraction of the uterus in pregnancy, while in more significant amounts, it can cause general spasm and constriction [8]. It is a popular natural cosmetic in Iranian and Indian medicine for improvement of skin complexion, and as a part of folk phytopreparation, it brightens the skin of the body [33].

In the cosmetic practice, this spice showed to be effective against acne, erysipelas, skin, wounds, and similar skin diseases, while in China, it is recommended for purpura, eczema, and measles $[8,30]$.

The aqueous extract of saffron, in combination with other medicinal drugs, is useful for the treatment of painful and dislocated joints, sprains, or fractured bones [29, 34]. Some nations use saffron to treat migraines or mental disorders such as depression and dementia. For example, in Iran, insomnia, severe headaches, and obstructions in the area of the head and the neck are cured with boiled water preparation of saffron, while in India, it is applied against depression and similar mental disorders $[1,30]$. Crocus sativus acts as an improving mood and calming anxiety agent [29]. The essential oil of saffron can be used as a sedative in combination with olive or sesame oil (as a medicine, the mixture of oils is left for five days with periodically stirring then filtered afterwards) [30]. The flowers of C. sativus are used as a part of alternative therapy for Alzheimer's disease [26].

Saffron is regarded as a stomachic and carminative drug, helpful for the liver, spleen, and stomach irregularities [29]. Also, it demonstrates emetic activity and can relieve problems with dyspepsia and to decrease appetite [30]. It helps with obesity-related metabolic disorders like hyperlipidemia and diabetes. Regarding this, the role of saffron in action against obesity was later confirmed [34]. Considering the cardiovascular system, C. sativus is used for many purposes. As cardiotonic, it affects the heart and speeds the circulation.
As a result of better blood flow, other medicaments reach the targeted organs more quickly. Saffron is used in England with the purpose to strengthen and stimulate the heart by better nutrition caused by faster blood flow. Besides these functions, the drug is applied in China against anemia and to prevent coagulation by breaking the blood clots $[29,34]$. In both Western and Eastern parts of the world, it is used as a medicine for problems with the respiratory system [30]. The saffron essential oil quickens the lung's function, relaxes the breathing, and is recognized as an expectorant. It is known to combat coughs and colds, partly by its specific odor, as well as asthma, pleurisy, and diaphragmatic [32]. Additionally, the plant helps with urinary infections. Traditionally, it is used as a herbal antispasmodic remedy that prevents obstructed urination.

The diuretic combination of saffron and honey helps to release kidney stones [30]. Crocus sativus is a folk medicament advised for irregularities in the menstrual cycle, which expresses many beneficial roles in the female reproductive system. It alleviates dysmenorrhea and has an emmenagogue application. Saffron relieves the pain in the uterus when combined with other drugs. Also, it can be used against uterus ulcers when applied with wax or yolk and olive oil. Crocus sativus is an aphrodisiac drug recognized for treatment of impotence. It has a traditional role in sperm activation. As already mentioned, it demonstrates abortive activity in larger amounts which can cause the uterus spasm and abortion in the pregnancy. Also, it is popularly used as a postlabour antiseptic in cows $[29,30,35]$.

According to literature data, other Crocus species are also utilized as natural phytotherapeutics. It is claimed in Iranian natural medicine that the endemic species $C$. caspius is medicinally effective against microbial infections [24]. The infusion of $C$. hyemalis aerial parts and stigma's filaments is recommended as an antitussive and antiasthmatic remedy and as a medicine for respiratory problems [23]. Furthermore, the significance of C. vernus in mountainous areas of Italy is expressed through the use of its flowers or entire flowering plant as an antiseptic, while the flower buds are advised externally against lice [27]. It was cited in traditional books that the mixture of C. sativus, Cyperus rotundus L., honey, and currant refreshes the memory and reduces forgetfulness and distraction [26].

Many beneficial properties of Crocus species are mainly related to a variety of carotenoids and their crocetin-type derivatives [1, 27]. The most important findings on the health-promoting effects of saffron are confirmed for cardiovascular ailments like blood pressure (BP), atherosclerosis, and coronary artery diseases. Furthermore, studies have confirmed that it impacts ocular blood flow, retinal function, and learning behavior, and it demonstrates anti-inflammatory, cytotoxic, and contraceptive activities [31].

\section{Phytochemical Composition}

Because of its wide range of pharmacological uses, saffron has undergone extensive biochemical and phytochemical studies (Supplementary material (available here), Tables 1 and 2), and several biologically active compounds have been 
isolated. Each of these bioactive compounds has characteristic inherent properties (Figure 1).

Saffron showed antimicrobial effects and can protect foods from microbial attack. Saffron flower petals are rich in phenolic compounds showing antimicrobial and antioxidant activity. Crocin is the most powerful antibacterial agent in saffron, particularly against Gram-negative bacteria like Escherichia coli. The high antibacterial activity of crocin is attributed to the alcoholic groups $(-\mathrm{OH})$ in its structure.

The peculiar quality and sensory properties in terms of aroma and taste have been attributed to three main bioactive compounds, crocin, picrocrocin, and safranal [36-38]. It also contains many nonvolatile components like lycopene, $\alpha$ - and $\beta$-carotene, and zeaxanthin [39].

The crocins, hydrophilic compounds, are considered the main active constituents that give saffron the golden yelloworange color [40-42]. Picrocrocin is responsible for the bitter taste (the bitter glucoside) [43, 44]. Safranal, a monoterpene aldehyde, produces the characteristic odor and aroma. [45-47].

These bioactive compounds are the degradation products of carotenoids, i.e., derived from oxidative cleavage zeaxanthin carotenoid, and are known as apocarotenoids [48, 49]. Additional bioactive compounds that are present include carbohydrates, flavonoids, gum, minerals, proteins, sugars, and vitamins, which have been isolated and reported from the saffron stigma $[47,50,51]$.

\section{Pharmacological Activities}

Traditional and alternative medicine has a significant impact on the current trends in preclinical and clinical research of medicinal plants [52-54]. Since saffron is a popular folk remedy in many countries, recent preclinical studies verified its wide application and the use of related Crocus species for medical purposes.

\subsection{In Vitro studies}

5.1.1. Cytotoxic Activity. Cancer is a term used to describe malignancies in which abnormal cells multiply in an uncontrolled and continuous manner and can invade the surrounding healthy tissues [53-55]. Abnormal cells come from any tissue in the human body and can occur anywhere in the body [56, 57]. The malignancies caused by this uncontrolled multiplication are numerous and difficult to control therapeutically $[58,59]$.

Antitumor effects of Crocus plant derivatives have been highlighted in a wide variety of isolated cell study models. The viability of healthy cells remained unaffected under treatment, while compared to malignant cells, including human cancer cells, saffron develops selective cytotoxic effects at micromolar doses.

Aqueous extract of saffron used in different concentrations $(100,200,400$, and $800 \mu \mathrm{g} / \mathrm{mL})$ exhibited cytotoxic and proapoptotic effects when investigated on lung cancer cell line A549. It was found that saffron reduced the proliferation of the A549 cells in a dose-dependent manner. In addition, it induced morphological changes, reduced the number of viable cells, and induced apoptosis. The $\mathrm{IC}_{50}$ against $\mathrm{A} 549$ cells was 380 and $170 \mu \mathrm{g} / \mathrm{mL}$ after 48 and 72 hours, as reported by Samarghandian et al. [60].

Another study conducted by Vali et al. [61] on a breast cancer cell line (MCF-7), a synergistic effect was found between combinations of crocin with gamma radiation or paclitaxel in increasing apoptosis and decreasing survival rate of the cells. The MTT assay was used to determine the $\mathrm{IC}_{50}(3.5 \mathrm{mg} / \mathrm{mL})$ of crocin after 48 -hour treatment. Also, the treatment of MCF-7 with crocin at different time intervals increased apoptosis of the cells as detected by flow cytometry, where the combined therapy of crocin and paclitaxel increased apoptosis significantly over single therapy. On the other hand, the combined therapy caused an increase in the expression of caspase-7, caspase-9, P53, and poly (ADP-ribose) polymerase (PARP) [61].

Another approach was taken Mousavi et al. [62] on the MCF-7 cell line treated with aqueous saffron extract (100, 200,400 , and $800 \mu \mathrm{g} / \mathrm{mL}$ ) using the trypan blue assay to investigate the morphological changes of cells under an inverted microscope as well as gene expression of matrix metalloproteinase (MMP). The treatment groups showed a significant reduction in MMP gene levels compared to the control group. Since MMPs regulate the signaling pathway that controls cell growth, inflammation, or angiogenesis, MMPs may be a target in cancer treatment and metastasis inhibition.

An earlier study was performed in which HeLa cells were treated with an ethanolic extract of saffron and its compounds. The $\mathrm{IC}_{50}$ for the ethanolic extract was $2.3 \mathrm{mg} / \mathrm{mL}$, $3 \mathrm{mM}$ for crocin and picrocrocin, separately, and $0.8 \mathrm{mM}$ for safranal. Crocin, safranal, and picrocrocin showed a dose-dependent inhibition of cell growth, while crocetin did not show any effect on cell proliferation [63].

Sun et al. [64] examined the effect of crocin on human promyelocytic leukaemia cells and HL-60 cells in vitro where they found that crocin $(0.625-10 \mathrm{mg} / \mathrm{mL})$ significantly inhibited HL-60 cell proliferation dose-dependently and induced cell cycle arrest at G0-G1 phase in HL-60 by flow cytometry using propidium iodide staining.

Another study was performed by Tuberoso et al. [65] in which cytotoxicity of saffron juice was evaluated by MTT assay on Caco- 2 colon cancer cell line; the cell viability was $30 \%$ at $48 \mathrm{~h}$ treatment with saffron juice $(10 \mu \mathrm{L} / \mathrm{mL})$, while at $24 \mathrm{~h}$ treatment, cell viability was $32 \%$ but only at a higher concentration $(50 \mu \mathrm{L} / \mathrm{mL})$.

5.1.2. Antimicrobial Activity. Bacterial infections can trigger various diseases such as pneumonia, otitis, diarrhea, and skin infections and are the result of severe infections with germs difficult to treat such as bacteria in the category of Gram-negative germs Enterobacteriaceae, Streptococci, Escherichia coli, or Salmonella [66, 67]. The main method of fighting bacterial infections is antibiotic treatment [68]. Although they are effective in most cases, their widespread use has led to antibiotic resistance. This phenomenon consists in the adaptation of bacteria and, consequently, to difficulties in treating infections. Due to the use of antibiotics, the saprophytic microbial flora is destroyed, the flora that 
TABLE 1: In vitro biological activities of Crocus plants.

\begin{tabular}{|c|c|}
\hline Extract/compound & Tested cell lines/methods of analysis \\
\hline \multicolumn{2}{|l|}{ Cytotoxic activity } \\
\hline & $\begin{array}{c}\text { A549 lung cancer cells } \\
\text { MTT }\end{array}$ \\
\hline Saffron/aqueous extract & $\begin{array}{l}\text { Morphological change: inverted } \\
\text { microscope } \\
\text { Apoptosis: flow cytometry }\end{array}$ \\
\hline & $\begin{array}{c}\text { MCF-7 breast cancer cells } \\
\text { MTT }\end{array}$ \\
\hline Crocin/aqueous extract & $\begin{array}{c}\text { Apoptosis: flow cytometry } \\
\text { Caspase-7, caspase-9, P53, and PARP: } \\
\text { western blot }\end{array}$ \\
\hline $\begin{array}{l}\text { Saffron and its derivatives/ethanolic } \\
\text { extract }\end{array}$ & $\begin{array}{l}\text { HeLa human cervical epithelioid } \\
\text { carcinoma cells } \\
\text { Cytotoxicity assay } \\
\text { Morphological change: microscopy }\end{array}$ \\
\hline Saffron & $\begin{array}{l}\text { HeLa human cervical epithelioid } \\
\text { carcinoma cells colony formation } \\
\text { inhibitory assay }\end{array}$ \\
\hline Crocin & $\begin{array}{c}\text { HL-60 leukaemia cells } \\
\text { Apoptosis: flow cytometry } \\
\text { MTT }\end{array}$ \\
\hline Saffron juice & $\begin{array}{c}\text { Caco-2 colon cancer cells } \\
\text { MTT }\end{array}$ \\
\hline
\end{tabular}

Saffron/aqueous extract

Antimicrobial activity

Crocus sativus/petroleum ether, methanolic extracts

Crocus sativus/two extracts one contained the aglycon part of flavonoids the other contained flavonoids glycosides

Saffron/aqueous extract

Antioxidant activity

Crocus chrysanthus (Herb.)/ethyl acetate, methanol, and water extracts

Crocin, saffron/ethanolic extract

Saffron/ethanolic, methanolic extract

Saffron/corms, tepals, and leaves

Saffron/aqueous extract

Antidiabetic

Crocus chrysanthus (Herb.)/ethyl acetate, methanol, and aqueous extracts

MCF-7 breast cancer cells gene expression level of MMP using RT PCR trypan blue test

Agar well diffusion

Agar well diffusion

Modified well plate test

DPPH reductive potentials, metal chelating phosphomolybdenum method

Antihemolysis activity DPPH, lipid peroxidation Phosphomolybdenum method

DPPH ferric reducing antioxidant power

$\beta$-Carotene/linoleate model system, reducing power, DPPH, NO, radical scavenging, iron, and copper chelation

Bronchial epithelial cells

$\alpha$-Glucosidase inhibition $\alpha$-Amylase inhibition
Effect/mechanisms

Ref.

$$
\mathrm{IC}_{50}=390 \mu \mathrm{g} / \mathrm{mL}
$$

Inhibition and shrinkage of cancer cells $\uparrow$ percentage of early and late apoptotic cells

$$
\mathrm{IC}_{50}=3.5 \mathrm{mg} / \mathrm{mL}
$$

Crocin and paclitaxel: $\uparrow$ apoptosis, $\uparrow$ caspase- 7 ,

$$
\uparrow \text { caspase-9, } \uparrow \text { p53, and } \uparrow \text { PARP }
$$

$\mathrm{IC}_{50}=2.3 \mathrm{mg} / \mathrm{mL}$ for saffron, $\mathrm{IC}_{50}=3 \mathrm{mM}$ for crocin, $\mathrm{IC}_{50}=0.8 \mathrm{mM}$ for safranal, and $\mathrm{IC}_{50}=3$ $\mathrm{mM}$ for picrocrocin $\uparrow$ cytotoxicity

$\downarrow$ tumor cell growth

Trans-crocin 3: inhibitory effect

$$
\mathrm{IC}_{50}=0.625-10 \mathrm{mg} / \mathrm{mL}
$$

$\downarrow$ cell proliferation dose-dependently

$\uparrow$ cell cycle arrest at the G0-G1 phase

$$
\begin{gathered}
\mathrm{IC}_{50}=50 \mu \mathrm{L} / \mathrm{m} \\
\downarrow \text { cell viability }
\end{gathered}
$$

$\downarrow$ MMP gene expression

Petroleum ether extract: effective against Proteus vulgaris, Bacillus subtilis, Pseudomonas aeruginosa methanolic extract: $\downarrow$ development of

$$
\text { S. aureus, E. coli }
$$

The extract that contained the glycosidic part of flavonoids exhibited weak antimicrobial activity

$\downarrow$ growth inhibition zone tested pathogens: E. coli, S. aureus, and S. faecalis

The water extract showed the most powerful antioxidant activity

The saffron extract exhibited $107 \mathrm{mg} \alpha$ tocopherol/g DPPH radical-scavenging activity and 98.3, 90.8, and $33.1 \mathrm{mg} \alpha$-tocopherol/g, respectively, for crocin-1, crocin-2, and crocin-3 Methanolic extract $300 \mu \mathrm{g} / \mathrm{mL}$ : $\uparrow$ antioxidant activity

The best antioxidant activity: leaves and tepal extract, the least antioxidant activity: corms

$\downarrow N O, \downarrow$ iNOS, and $\downarrow$ peroxynitrite ion generation $\downarrow$ cytochrome $\mathrm{c}$ release

$\alpha$-Glucosidase inhibition: $14.8-1.89 \mathrm{mmol}$ acarbose equivalent/g according to different 
TABLE 1: Continued.

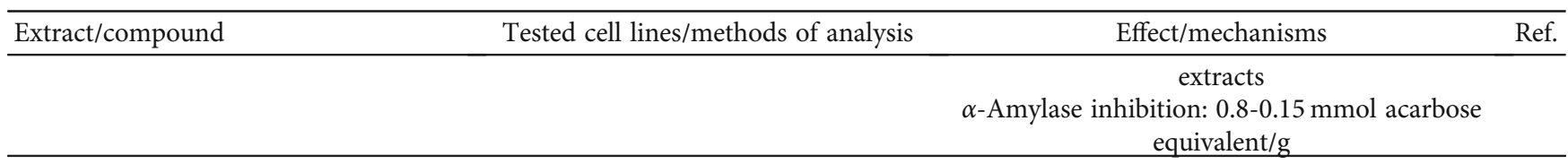

Abbreviations and symbols: $\uparrow$ increased, $\downarrow$ decreased, 2,2-diphenyl-1-picryl-hydrazyl-hydrate (DPPH), induced nitric oxide synthase (iNOS), nitric oxide (NO), and poly (ADP-ribose) polymerase (PARP).

facilitates digestion and supports the immune system. Thus, side effects such as gastrointestinal disorders, diarrhea, and allergic reactions occur. Therefore, alternative natural treatments with proven antibacterial effects are an important antimicrobial alternative.

Antimicrobial activity of C. sativus extracts (500, 750, and $1,000 \mu \mathrm{g} / \mathrm{disc}$ ) was evaluated by the presence or absence of inhibition zone and zone diameter [69]. Maximum zone inhibition of the petroleum ether extract was shown against Proteus vulgaris, Bacillus subtilis, and Pseudomonas aeruginosa, whereas the methanolic extract showed maximum zone inhibition against $S$. aureus and E. coli, as demonstrated by Muzaffar et al. [69].

Kakouri et al. [70] investigated the antimicrobial activity of two extracts of $C$. sativus tepals. One extract contained the aglycon part of flavonoids and the other contained flavonoids glycosides. The antimicrobial activity of the extracts was evaluated against six bacterial species by well diffusion assay, where the extract that contained the glycosidic part of flavonoids exhibited weak antimicrobial activity. The best antimicrobial capacity was presented by tepal extract containing aglycons. Results from a study conducted by Hussein et al. [71] indicated strong antibacterial activity of the saffron extract against E. coli and Staphylococcus aureus at a concentration of $100 \mu \mathrm{g} / \mathrm{mL}$. They claimed that the methanolic extract of crocin possesses the highest antibacterial activity against $E$. coli and $S$. aureus compared to other saffron pigments. They found that the antibacterial effect of crocin is approximately equal to chloramphenicol and ciprofloxacin (known as standard antibiotics) at $100 \mu \mathrm{g} / \mathrm{mL}$ concentration [71].

Another study was performed to assess the antimicrobial activity of aqueous extract of $C$. sativus collected from different areas in Iran using 3 different bacteria by a modified well plate test where different concentrations of extract were done and evaluated based on growth inhibition zone in which some of them had antimicrobial (S. aureus and E. faecalis) activity while others had no detectable activity (E. coli) [72].

5.1.3. Antioxidant Activity. Oxidative stress is the term used for diseases caused by reactive oxygen species (ROS) called free radicals $[73,74]$ and is defined as the imbalance between oxidants and antioxidants, in favor of oxidants, with destructive and pathogenetic potential $[75,76]$. Depending on the intensity, oxidative stress can occur intra- or extracellularly [77]. Intracellular oxidative stress can cause cell necrosis or more or less marked cell disorganization, with catastrophic effects in the case of a cell that cannot reproduce. Extracellular oxidative stress is also cytotoxic $[78,79]$
(Figure 2). Among the saffron constituents, crocetin has stronger antioxidant activity (DPPH (2,2-diphenyl-1picryl-hydrazyl-hydrate)) than safranal, and the potential of crocetin was equivalent to that of Trolox and butyl hydroxyl toluene (BHT) [80].

Crocin, ethanolic extract of saffron, and different extracts of $C$. chrysanthus were evaluated by different in vitro assays: antihemolysis, DPPH free radicalscavenging assay, in vitro lipid peroxidation, ferric reducing antioxidant power, phosphomolybdenum method, metal chelating, and reductive potentials [81-83]. The studied extracts and isolates from saffron exhibited significant antioxidant activity (Table 3); however, this activity is affected by the type of solvent used that is why they may be involved in the treatment of various diseases via free radical scavengers.

Another study was done to evaluate the antioxidant activity of corms, tepals, and leaves of saffron to increase the profitability of this crop in which the leaf extract showed the best antioxidant activity via total inhibition of the $\beta$-carotene oxidation at $10 \mu \mathrm{g} / \mathrm{mL}$ and a DPPH scavenger activity higher (up to 32 times) than those reported for traditional sources of antioxidants; a similar effect was shown with tepal extract, but in contrast, corm extract was a weak antioxidant [84].

Crocin had the stronger antioxidant capacity on rat pheochromocytoma (PC-12) cells than the standard antioxidant agent $\alpha$-tocopherol so that it could reverse the results of the cell membrane damage and enhanced superoxide dismutase (SOD) level in oxidatively stressed neurons [85]. Bukhari et al. [86] investigated in stressed bronchial epithelial cells by cytokine combination the effects of $C$. sativus. Saffron treatment and its constituents (safranal and crocin) decreased nitric oxide of (NO), induced nitric oxide synthase (iNOS) levels, and peroxynitrite ion generation and prevented cytochrome c release.

Saffron constituents reduced lipid peroxidation [87] and prevented the increase of oxidative stress markers induced by diazinon through free radical-scavenging activity [88]. Moreover, a mitochondrial and lipid peroxidation protection against 3-nitropropionic acid toxin has also been reported in striatal synaptosomes isolated from rat brain [89].

A summarized scheme with the most representative antioxidant mechanisms of phytocompounds of Crocus sativus L. is shown in Figure 2.

\subsection{In Vivo studies, cellular, and molecular pharmacology}

\subsubsection{Effects on Cardiovascular System}


TABLE 2: In vivo evaluation of the pharmacological properties of Crocus plant.

\begin{tabular}{|c|c|c|c|c|c|}
\hline Plant/compound/extract & Doses & Route & Model & Main pharmacological effect & Ref. \\
\hline Crocetin & $100 \mathrm{mg} / \mathrm{kg}$ & Oral & $\begin{array}{l}\text { Rats stroke-prone } \\
\text { spontaneously hypertensive rats } \\
\text { high-oxidative stress model }\end{array}$ & $\begin{array}{c}\text { Antioxidant } \\
\downarrow \text { oxidative stress, } \downarrow \text { ROS in rats brain }\end{array}$ & {$[95]$} \\
\hline $\begin{array}{l}\text { Crocus sativus L./aqueous } \\
\text { extract }\end{array}$ & $\begin{array}{l}10,20, \text { and } \\
40 \mathrm{mg} / \mathrm{kg}\end{array}$ & i.p. & $\begin{array}{c}\text { Rats } \\
\text { STZ-induced diabetes }\end{array}$ & $\begin{array}{c}\text { Antihyperglycemic } \\
\downarrow \text { blood glucose, } \downarrow \text { MDA, } \downarrow \text { NO, } \downarrow \text { lipids, } \downarrow \text { TG, } \\
\downarrow \text { cholesterol, } \uparrow \text { glutathione level, } \uparrow \text { CAT, } \\
\uparrow \text { SOD } \downarrow \text { inflammatory cytokines }\end{array}$ & [180] \\
\hline $\begin{array}{l}\text { Crocus sativus L./aqueous, } \\
\text { ethanol extracts }\end{array}$ & $500 \mathrm{mg} / \mathrm{kg}$ & i.v. & Rats, guinea pigs & $\begin{array}{c}\text { Antihypertensive } \\
\downarrow \text { blood pressure in a dose-dependent } \\
\text { manner }\end{array}$ & {$[100]$} \\
\hline Crocetin & $20 \mathrm{mg} / \mathrm{kg}$ & Oral & $\begin{array}{l}\text { Lung cancer-bearing mice } \\
\text { benzo(a)pyrene- }(\mathrm{B}(\mathrm{a}) \mathrm{p}-) \\
\text { induced lung carcinoma }\end{array}$ & $\begin{array}{c}\text { Antitumor } \\
\text { } \text { activities of enzymatic antioxidants } \\
\uparrow \text { glutathione metabolizing enzymes }\end{array}$ & [203] \\
\hline Crocetin & $50 \mathrm{mg} / \mathrm{kg}$ & i.p. & $\begin{array}{c}\text { Mice } \\
\text { Benzopyrene-induced lung } \\
\text { cancer model }\end{array}$ & $\begin{array}{c}\text { Antitumor } \\
\downarrow \text { proliferating cells }\end{array}$ & [204] \\
\hline Zhejiang saffron & $100 \mathrm{mg} / \mathrm{kg}$ & Oral & $\begin{array}{l}\text { Mice } \\
\text { Xenograft tumor }\end{array}$ & $\begin{array}{c}\text { Antitumor } \\
\downarrow \text { tumor size via caspase-3, caspase- } 8 \text {, } \\
\text { caspase- } 9 \text {, and } \uparrow \text { apoptosis }\end{array}$ & [205] \\
\hline Saffron/aqueous infusion & $\begin{array}{c}50- \\
500 \mathrm{mg} / \mathrm{kg}\end{array}$ & Oral & $\begin{array}{l}\text { Mice } \\
\text { DMBA-induced skin } \\
\text { carcinogenesis }\end{array}$ & $\begin{array}{c}\text { Antitumor } \\
\downarrow \text { papilloma cells formation }\end{array}$ & [206] \\
\hline Saffron/aqueous extract & $100 \mathrm{mg} / \mathrm{kg}$ & Topical & $\begin{array}{c}\text { Mice } \\
\text { DMBA, croton oil-induced skin } \\
\text { carcinogenesis, MCA-induced } \\
\text { soft tissue sarcomas }\end{array}$ & $\begin{array}{c}\text { Antitumor } \\
\downarrow \text { tumor formation }\end{array}$ & [207] \\
\hline Saffron & $\begin{array}{c}400, \\
800 \mathrm{mg} / \mathrm{kg}\end{array}$ & Oral & $\begin{array}{c}\text { Rats } \\
\text { PTZ-induced seizures }\end{array}$ & $\begin{array}{c}\text { Anticonvulsant } \\
\downarrow \text { seizures frequency in a dose-dependent } \\
\text { manner }\end{array}$ & [128] \\
\hline Safranal & $\begin{array}{l}0.15 \\
0.35 \mathrm{~mL} / \\
\mathrm{kg}\end{array}$ & i.p. & $\begin{array}{c}\text { Mice } \\
\text { PTZ-induced seizures }\end{array}$ & $\begin{array}{l}\text { Anticonvulsant } \\
\downarrow \text { seizures duration, delayed the onset of } \\
\text { tonic convulsions }\end{array}$ & {$[16]$} \\
\hline Safranal & $\begin{array}{l}72.75 \\
145.5, \text { and } \\
290 \mathrm{mg} / \mathrm{kg}\end{array}$ & i.p. & $\begin{array}{c}\text { Rats } \\
\text { PTZ-induced seizures }\end{array}$ & $\begin{array}{l}\text { Anticonvulsant } \\
\downarrow \text { MCS, } \downarrow \text { GTCS }\end{array}$ & {$[17]$} \\
\hline Crocin & $200 \mathrm{mg} / \mathrm{kg}$ & i.p. & $\begin{array}{c}\text { Mice } \\
\text { PTZ-induced seizures }\end{array}$ & It did not show anticonvulsant activity & {$[16]$} \\
\hline $\begin{array}{l}\text { C. sativus L./hydroethanolic } \\
\text { extract }\end{array}$ & $50 \mathrm{mg} / \mathrm{kg}$ & Oral & $\begin{array}{c}\text { Meriones shawi } \\
\text { Pb-intoxicated ( } 25 \mathrm{mg} / \mathrm{kg} \text { bw, } \\
\text { i.p.) }\end{array}$ & $\begin{array}{c}\text { Neuroprotective } \\
\uparrow \mathrm{TH} \text { in SNC, VTA, LC, DS, and MFB } \\
\uparrow \text { locomotor activity, } \downarrow \text { dysfunction in Pb- } \\
\text { intoxicated meriones }\end{array}$ & [141] \\
\hline Crocetin & $\begin{array}{l}25,50 \\
75 \mu \mathrm{g} / \mathrm{kg}\end{array}$ & i.p. & $\begin{array}{l}\text { Rats } \\
\text { 6-Hydroxydopamine }(10 \mu \mathrm{g} \\
\text { intrastriatal) } \\
\text { Induced Parkinson's disease }\end{array}$ & $\begin{array}{c}\text { Neuroprotective } \\
\downarrow \text { dopamine utilization by tissues }\end{array}$ & [145] \\
\hline Saffron & $0.01 \% w / v$ & Oral & $\begin{array}{c}\text { BALB-c mice } \\
\text { MPTP-induced Parkinson's } \\
\text { disease }\end{array}$ & $\begin{array}{c}\text { Neuroprotective } \\
\downarrow \text { ROS, } \uparrow \text { antioxidant effect } \rightarrow \text { protect } \\
\text { dopaminergic cells }\end{array}$ & [146] \\
\hline C. sativus L./stigma extract & $100 \mathrm{mg} / \mathrm{kg}$ & Oral & $\begin{array}{c}\text { Rats } \\
\text { Induction of cerebral ischemia } \\
\text { MCAO }\end{array}$ & $\begin{array}{c}\text { Neuroprotective } \\
\downarrow \text { SOD, } \downarrow \mathrm{CAT}, \downarrow \mathrm{Na}^{+} \text {, and } \mathrm{K}^{+} \text {-ATPase } \\
\text { activities } \\
\downarrow \text { glutamate, } \downarrow \text { aspartate induced by ischemia }\end{array}$ & [164] \\
\hline Saffron/honey syrup & $\begin{array}{l}200, \\
500 \mathrm{mg} / \mathrm{kg}\end{array}$ & Oral & $\begin{array}{c}\text { Mice } \\
\text { Aluminum chloride-induced } \\
\text { neurotoxicity }\end{array}$ & $\begin{array}{l}\text { Neuroprotective } \\
\downarrow \text { neurotoxicity }\end{array}$ & [208] \\
\hline
\end{tabular}


TABLE 2: Continued.

\begin{tabular}{|c|c|c|c|c|c|}
\hline Plant/compound/extract & Doses & Route & Model & Main pharmacological effect & Ref. \\
\hline Saffron/aqueous extract & $\begin{array}{l}50,100 \\
200 \mathrm{mg} / \mathrm{kg}\end{array}$ & Oral & $\begin{array}{c}\text { Rats } \\
\text { Diazinon- }(20 \mathrm{mg} / \mathrm{kg}) \text { induced } \\
\text { neurotoxicity }\end{array}$ & $\begin{array}{c}\text { Neuroprotective } \\
\downarrow \text { inflammation, } \downarrow \text { oxidative stress, and } \\
\downarrow \text { neuronal damage }\end{array}$ & {$[88]$} \\
\hline Crocin & $\begin{array}{l}30,60, \\
120 \mathrm{mg} / \mathrm{kg}\end{array}$ & Oral & $\begin{array}{l}\text { Rats } \\
\text { Ischemia/reperfusion injury } \\
\text { model of stroke }\end{array}$ & $\begin{array}{c}\text { Neuroprotective } \\
\text { Crocin } 60 \mathrm{mg} / \mathrm{kg} \rightarrow \downarrow \text { brain oedema }\end{array}$ & [158] \\
\hline Crocetin & $50 \mathrm{mg} / \mathrm{kg}$ & Oral & $\begin{array}{c}\text { Rats } \\
\text { Induced cerebral contusion }\end{array}$ & $\begin{array}{c}\text { Neuroprotective } \\
\uparrow \text { neurological function, } \downarrow \text { neuronal apoptosis } \\
\uparrow \text { VEGFR-2, } \uparrow \text { SRF }\end{array}$ & [155] \\
\hline Crocin & $\begin{array}{l}25,50 \mathrm{mg} / \\
\mathrm{kg}\end{array}$ & i.p. & $\begin{array}{l}\text { Rats } \\
\text { Retinal damage induced by } \\
\text { †intraocular pressure }\end{array}$ & $\begin{array}{c}\text { Retinal damage protection } \\
\uparrow \mathrm{RGCs,} \mathrm{\downarrow apoptosis,} \mathrm{and} \uparrow \mathrm{PI} 3 \mathrm{~K} / \mathrm{AKT}\end{array}$ & [197] \\
\hline Crocetin & $100 \mathrm{mg} / \mathrm{kg}$ & Oral & $\begin{array}{l}\text { Mice } \\
\text { N-Methyl-d-aspartate in the } \\
\text { murine retina }\end{array}$ & $\begin{array}{c}\text { Retinal damage protection } \\
\downarrow \text { NMDA, } \downarrow \text { GCL cell number, } \downarrow \text { TUNEL- } \\
\text { positive cells, } \downarrow \text { b-wave amplitude, } \uparrow \text { caspase- } \\
3 / 7 \text {, and } \uparrow \text { caspase- } 3 \text { in the GCL }\end{array}$ & [195] \\
\hline Saffron/aqueous extract & $\begin{array}{l}50,100 \\
150, \text { and } \\
250 \mathrm{mg} / \mathrm{kg}\end{array}$ & i.p. & Rats & $\begin{array}{c}\text { Effect on brain neurotransmitters } \\
\uparrow \text { dopamine, } \uparrow \text { glutamate in a dose-dependent } \\
\text { manner } \\
\text { No effect on brain serotonin, } \\
\text { norepinephrine }\end{array}$ & [209] \\
\hline $\begin{array}{l}\text { Saffron/aqueous, ethanolic } \\
\text { extracts }\end{array}$ & $\begin{array}{c}80-320 \\
400- \\
800 \mathrm{mg} / \mathrm{kg}\end{array}$ & i.p. & $\begin{array}{c}\text { Mice } \\
\text { Naloxone-induced model }\end{array}$ & $\begin{array}{c}\text { Effect on opioid system } \\
\downarrow \text { morphine withdrawal signs } \\
\downarrow \text { locomotor activity (open-field test) }\end{array}$ & [171] \\
\hline $\begin{array}{l}\text { Saffron/ethanolic extract } \\
\text { safranal }\end{array}$ & $\begin{array}{l}10,50 \text {, and } \\
100 \mathrm{mg} / \mathrm{kg} \\
1,5, \text { and } \\
10 \mathrm{mg} / \mathrm{kg}\end{array}$ & i.p. & Mice & $\begin{array}{l}\text { Effect on opioid system } \\
\downarrow \text { acquisition, } \downarrow \text { expression of morphine } \\
\text { conditioning place preference }\end{array}$ & [210] \\
\hline Crocin & $\begin{array}{c}400, \\
600 \mathrm{mg} / \mathrm{kg}\end{array}$ & i.p. & Mice & $\begin{array}{l}\text { Effect on opioid system } \\
\downarrow \text { acquisition, } \downarrow \text { reinstatement of morphine- } \\
\text { induced conditioning place preference }\end{array}$ & [211] \\
\hline $\begin{array}{l}\text { Crocus sativus L./ethanolic } \\
\text { extract from stigma }\end{array}$ & $\begin{array}{l}5,10 \mu \mathrm{g} / \\
\mathrm{kg}\end{array}$ & $\begin{array}{l}\text { Intra- } \\
\text { accumbal }\end{array}$ & Rats & $\begin{array}{c}\text { Effect on opioid system } \\
\downarrow \text { time spent on the drug paired side, } \\
\downarrow \text { expression of morphine conditioning place } \\
\text { preference }\end{array}$ & [212] \\
\hline $\begin{array}{l}\text { Crocus sativus L./aqueous, } \\
\text { ethanolic extracts from } \\
\text { stigma safranal crocin }\end{array}$ & $\begin{array}{l}\text { Extracts } \\
0.2-0.8 \mathrm{~g} / \\
\mathrm{kg} \\
\text { Safranal } \\
0.15- \\
0.5 \mathrm{~mL} / \mathrm{kg} \\
\text { Crocin } 50- \\
600 \mathrm{mg} / \mathrm{kg}\end{array}$ & i.p. & $\begin{array}{c}\text { Mice } \\
\text { Forced open-field swimming } \\
\text { test }\end{array}$ & $\begin{array}{c}\text { Antidepressant } \\
\text { Extracts, safranal, crocin: } \downarrow \text { immobility time, } \\
\uparrow \text { stereotypic activities } \\
\text { Safranal: } \uparrow \text { swimming time } \\
\text { Safranal and crocin: } \uparrow \text { climbing time } \\
\text { Crocin: } \uparrow \text { dopamine, } \uparrow \text { norepinephrine } \\
\text { Safranal: } \uparrow \text { serotonin }\end{array}$ & {$[18]$} \\
\hline $\begin{array}{l}\text { Crocus sativus L./aqueous } \\
\text { extract }\end{array}$ & $30 \mathrm{mg} / \mathrm{kg}$ & ICV & $\begin{array}{c}\text { Rats } \\
\text { STZ-ICV Alzheimer's disease } \\
\text { model }\end{array}$ & $\begin{array}{c}\text { Anti-Alzheimer } \\
\downarrow \text { cognitive deficits } \\
\text { †learning, } \uparrow \text { memory via metabolism/ } \\
\text { enzyme mechanisms, no anatomical } \\
\text { structural repair involved }\end{array}$ & [136] \\
\hline Saffron & $60 \mathrm{mg} / \mathrm{kg}$ & i.p. & BALB-c mice adult and aged & $\begin{array}{c}\text { Cognitive enhancing effect } \\
\uparrow \text { learning, } \uparrow \text { memory (passive avoidance } \\
\text { behavior test) } \\
\downarrow \text { AChE in adult mice } \\
\text { No effect on AChE activity on aged mice }\end{array}$ & [213] \\
\hline Crocin & $30 \mathrm{mg} / \mathrm{kg}$ & ICV & $\begin{array}{c}\text { Rats } \\
\text { STZ-ICV Alzheimer's disease } \\
\text { model }\end{array}$ & $\begin{array}{c}\text { Anti-Alzheimer } \\
\uparrow \text { memory (passive avoidance test) } \\
\uparrow \text { spatial cognition (Y-maze task) }\end{array}$ & [137] \\
\hline
\end{tabular}


TABLE 2: Continued.

\begin{tabular}{|c|c|c|c|c|c|}
\hline Plant/compound/extract & Doses & Route & Model & Main pharmacological effect & Ref. \\
\hline Crocin & $\begin{array}{c}25- \\
100 \mathrm{mg} / \mathrm{kg}\end{array}$ & Oral & $\begin{array}{c}\text { Rats } \\
\text { Diet-induced hyperlipidemia }\end{array}$ & $\begin{array}{c}\text { Hypolipidemic } \\
\uparrow \text { faecal excretion of fat and cholesterol } \\
\text { Not influence the elimination of bile acids } \\
\downarrow \text { pancreatic lipase as a competitive inhibitor }\end{array}$ & {$[175]$} \\
\hline Crocin safranal & $\begin{array}{l}25,50 \text {, and } \\
100 \mathrm{mg} / \mathrm{kg} \\
0.5,1, \text { and } \\
2 \mathrm{mg} / \mathrm{kg}\end{array}$ & i.p.l. & $\begin{array}{l}\text { Rats } \\
\text { Local inflammation induced by } \\
\text { i.p.l. injection of carrageenan } \\
(100 \mu \mathrm{L}, 2 \%)\end{array}$ & $\begin{array}{c}\text { Anti-inflammatory } \\
\downarrow \text { oedema, } \downarrow \text { inflammatory pain responses } \\
\downarrow \text { neutrophils }\end{array}$ & [214] \\
\hline $\begin{array}{l}\text { Crocus sativus L./ethanolic } \\
\text { extract from stigma }\end{array}$ & $\begin{array}{l}20,40, \text { and } \\
80 \mathrm{mg} / \mathrm{kg}\end{array}$ & Oral & $\begin{array}{c}\text { Rats } \\
\text { Alloxan-induced diabetes }\end{array}$ & $\begin{array}{c}\text { Antihyperglycemic } \\
40 \mathrm{mg} / \mathrm{kg}: \downarrow \text { blood glucose, } \uparrow \text { serum insulin }\end{array}$ & {$[182]$} \\
\hline Safranal & $\begin{array}{l}0.2,0.5 \\
0.75 \mathrm{~mL} / \\
\mathrm{kg}\end{array}$ & Aerosol & $\begin{array}{l}\text { Guinea pigs' citric acid aerosol } \\
\text { for } 10 \mathrm{~min}\end{array}$ & $\begin{array}{c}\text { Antitussive } \\
\downarrow \text { cough count significantly as compared to } \\
\text { the saline-treated group }\end{array}$ & [189] \\
\hline \multicolumn{6}{|c|}{$\begin{array}{l}\text { Abbreviations and symbols: } \uparrow \text { increase, } \downarrow \text { decrease, body weight (bw), catalase (CAT), dimethylbenzene [a] anthracene (DMBA), dorsal striatum (DS), } \\
\text { generalized tonic-clonic seizures (GTCS), intracerebroventricular (ICV), intraperitoneal (i.p.), intraplantar (i.p.l.), intravenously (i.v.), locus coeruleus (LC), } \\
\text { 20-methylcholanthrene (MCA), 1-methyl-4-phenyl-1,2,3,6-tetrahydropyridine (MPTP), malondialdehyde (MDA), medial forebrain bundle (MFB), middle } \\
\text { cerebral artery occlusion (MCAO), minimal clonic seizures (MCS), nitric oxide (NO), pentylenetetrazole (PTZ), phosphatidylinositol 3-kinase (PI3K)/ } \\
\text { protein kinase B (AKT), reactive oxygen species (ROS), retinal ganglion cells (RGCs), serum response factor (SRF), substantia nigra compacta (SNc), } \\
\text { superoxide dismutase (SOD), streptozotocin (STZ), triglycerides (TG), tyrosine hydroxylase (TH), ventral tegmental area (VTA), and vascular endothelial } \\
\text { growth factor receptor-2 (VEGFR-2). }\end{array}$} \\
\hline
\end{tabular}
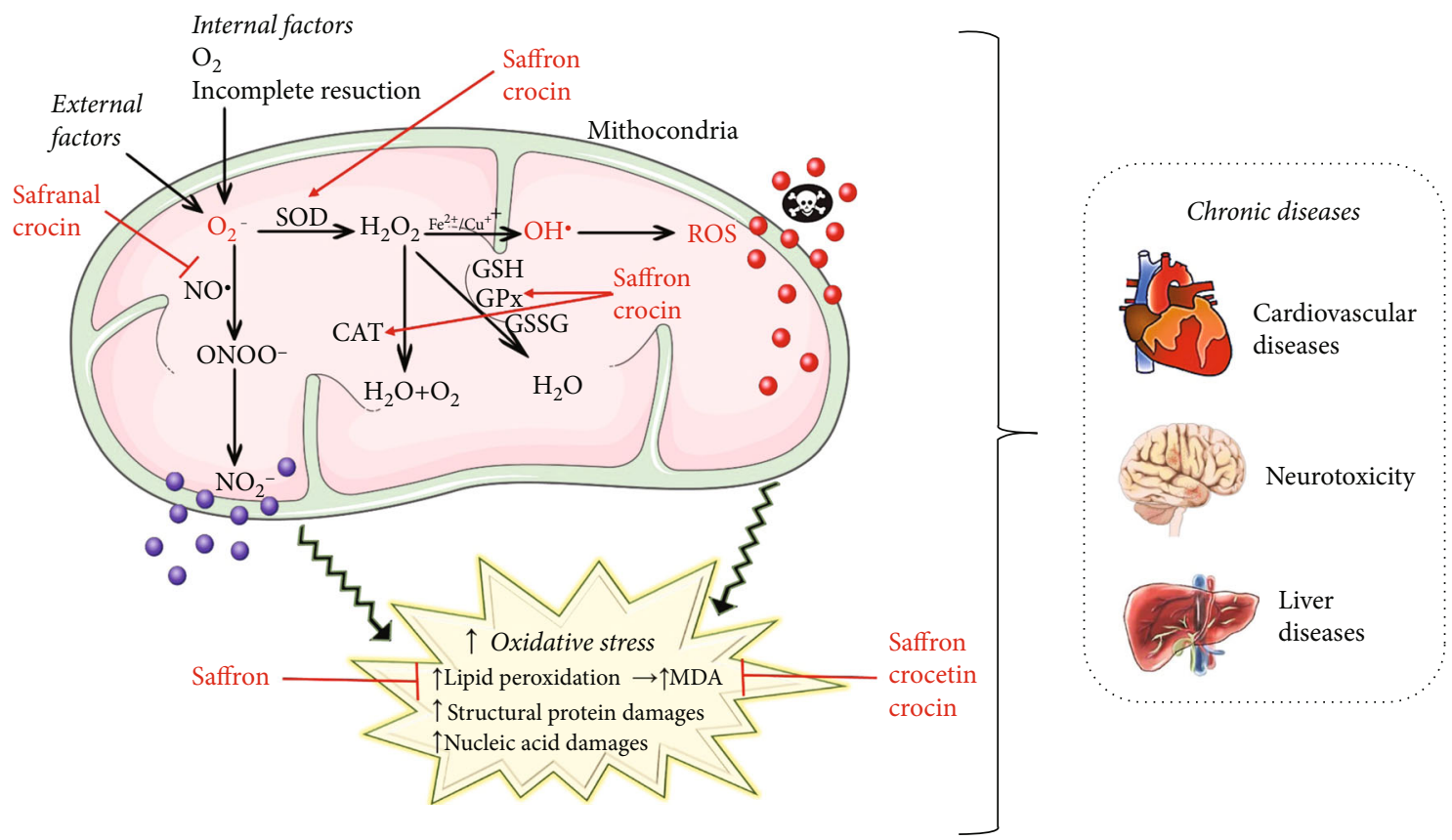

FIGURE 2: Illustrative scheme with different pathways of ROS formation and their impact on health. Bioactive compounds of Crocus sativus L. interfere with these mechanisms showing the beneficial effects for human health. Abbreviations and symbols: $\uparrow$ (increase, stimulate), $\nabla$ (decrease, inhibition), CAT (catalase), NO (nitric oxide), MDA (malondialdehyde), ROS (reactive oxidative species), glutathione peroxidase (GPx), GSSG (oxidized glutathione), GSH (reduced glutathione), $\mathrm{O}_{2}^{-}$(superoxide), $\mathrm{H}_{2} \mathrm{O}_{2}$ (hydrogen peroxide), $\mathrm{OH}^{\bullet}$ (hydroxyl ions), and NO (nitric oxide).

(1) Antihypertensive Effect. High BP is a major cardiovascular risk factor with a growing incidence [75]. High BP can be controlled with medication, but natural remedies with proven antihypertensive effects are also used as adjuvant therapy [91].

Crocus sativus extract and safranal were reported to stimulate $\beta 2$-adrenoreceptors $[92,93]$. Also, safranal can act as a muscarinic receptor blocker, and $C$. sativus has an inhibitory or even antagonistic effect on histamine (H1) receptors [93].

Crocetin has been reported to lower the BP [94]. Yoshino et al. [95] observed the antioxidant potential of crocetin in stroke-prone spontaneously hypertensive rats and a significant inhibition of hydroxyl radical generation.

Crocin and safranal have BP-modulating features, but the mechanism of action is still under investigation [96]. 
TABle 3: Clinical studies.

\begin{tabular}{|c|c|c|c|c|}
\hline Type of extract & Type of study & $\begin{array}{l}\text { Dose/ } \\
\text { period }\end{array}$ & Effect & References \\
\hline Saffron extract & $\begin{array}{l}\text { Randomized double-blind } \\
\text { clinical trial }\end{array}$ & $\begin{array}{l}30 \mathrm{mg} / \\
\text { day } \\
\text { Six } \\
\text { weeks }\end{array}$ & $\begin{array}{l}\text { Saffron supplements statistically improved the mood } \\
\text { of subjects compared to the placebo group based on } \\
\text { the Hamilton depression rating scale (HAM-D) }\end{array}$ & {$[222]$} \\
\hline Saffron extract & $\begin{array}{l}\text { Randomized double-blind } \\
\text { clinical trial }\end{array}$ & $\begin{array}{l}30 \mathrm{mg} / \\
\text { day for } \\
\text { six weeks }\end{array}$ & $\begin{array}{c}\text { Treatment of mild to moderate depression } \\
\downarrow \downarrow \text { clinical signs }\end{array}$ & [215] \\
\hline $\begin{array}{l}\text { Hydroalcoholic extract of } \\
\text { Crocus sativus L. } \\
\text { coadministered with } \\
\text { fluoxetine }\end{array}$ & $\begin{array}{l}\text { Randomized double-blind } \\
\text { clinical trial }\end{array}$ & $\begin{array}{c}\text { (40 or } \\
80 \mathrm{mg}) \\
(30 \mathrm{mg} / \\
\text { day) } \\
\text { Six } \\
\text { weeks }\end{array}$ & $\begin{array}{c}\text { C. sativus } 80 \mathrm{mg} \text { plus fluoxetine was more effective in } \\
\text { the treatment of mild to moderate depressive } \\
\text { disorders }\end{array}$ & [223] \\
\hline Crocin/aqueous extract & Clinical trial & $\begin{array}{l}15 \mathrm{mg} \\
\text { twice } \\
\text { daily }\end{array}$ & $\begin{array}{l}\text { Well tolerated by schizophrenic patients with no } \\
\text { severe side effects }\end{array}$ & {$[221]$} \\
\hline Saffron extract $\left(\right.$ Affron $\left.^{\circledR}\right)$ & $\begin{array}{l}\text { Randomized, double-blind, } \\
\text { placebo-controlled study, } \\
\text { youth aged } 12-16 \text { years }\end{array}$ & $\begin{array}{l}14 \mathrm{mg} \\
\text { twice } \\
\text { daily } \\
8 \text { weeks }\end{array}$ & Improved anxiety and depressive symptoms & [218] \\
\hline
\end{tabular}

Crocin and safranal showed a hypotensive effect in a dosedependent manner, being safranal more potent [97].

In addition, the cardioprotective role of saffron and its constituents has been reported [98]. The aqueous extract of saffron stigmas was reported to have an antihypertensive and normalizing effect on the BP of normotensive and desoxycorticosterone acetate (DOCA) salt-induced hypertensive rats [99]. Aqueous extract of saffron petals $(500 \mathrm{mg} / \mathrm{kg})$ reduced $\mathrm{BP}$ through its direct effect on the heart itself or the total peripheral resistance or both [100]. In rats' isolated vas deferens, contractile responses to electrical field stimulation were decreased by the petal extracts [100]; this effect was mediated by cotransmitter noradrenaline and ATP released from sympathetic nerves. Another study suggested that saffron exerted a significant cardioprotective effect by preserving hemodynamics and left ventricular functions [101].

(2) Antiarrhythmic effect. Saffron plays an important role in the electrophysiological remodeling of the atrioventricular (AV) node during atrial fibrillation [102]. Boskabady et al. [103] observed a potent inhibitory effect of saffron aqueous extract on the noradrenaline of the guinea pig's isolated heart. In patients with ischemic heart disease, crocin also can be utilized for the prevention or treatment of arrhythmias [104]. Crocin was tested against cardiac reperfusioninduced arrhythmia, where it showed a defensive role in cardiac reperfusion arrhythmias, through amplification of antioxidant systems [104].

Myocardial damage and arrhythmia are associated with increased malondialdehyde (MDA) level, decreased activity of antioxidant enzymes, accumulation of free radicals, and the effect on ion $\mathrm{Ca}^{2+}$ channels [105]. Inhibition of ADP and collagen-induced platelet aggregation by crocetin via inhibition of $\mathrm{Ca}^{2+}$ elevation in stimulated platelets have also been reported in a dose-dependent manner [106]. The suggested cardioprotective effect of saffron mechanism is antioxidant activity, recovery, and upregulation of antioxidant enzymes [107], e.g., glutathione peroxidase (GPx), by inhibition of cardiac calcium channels.

(3) Effect on Myocardial Ischemia. In isoproterenol- (ISO-) induced myocardial infarction rat model, Goyal et al. [108] observed a dose-dependent preventive effect of saffron through histopathological and ultrastructural examinations. In addition, intravenous crocin reduced myocardial injury and lactate dehydrogenase $(\mathrm{LDH})$ and creatine kinase $(\mathrm{CK})$ level [109]. Orally administration did not show the same effects, possibly because of the inefficient absorption.

(4) Antiatherosclerotic Effect in Cardiovascular Diseases. In bovine aortic endothelial cells, crocin regulated redox status in a dose-dependent pattern and exhibits regression and inhibition of atherosclerosis via apoptosis by increasing $\mathrm{Bcl}$ 2/Bax ratio expression [109]. Antiatherosclerotic effects of saffron were observed mainly because of crocetin that decreased the level of cardiac markers, e.g., $\mathrm{LDH}, \mathrm{CK}$, and MDA, besides increasing the mitochondrial potential in noradrenaline-treated cardiac myocytes [110].

Crocetin administration significantly decreased total cholesterol (TC) deposits in aorta, atheroma, foam cells, and atherosclerotic lesions in the crocetin fed animals [110]. A possible mechanism involved is due to suppression of nuclear factor- (NF-) $\kappa \mathrm{B}$, which in turn decreases the vascular cell adhesion molecule-1 (VCAM-1) expression [111]. This antiatherosclerotic effect of crocetin has been also 
attributed to its antioxidant activity that decreases ROSinduced MDA levels [101]. In another study, crocetin decreased the TC level in the blood and thus reduced the risk of atherosclerosis and heart attacks. This effect may be due to the reinforcement of blood circulation [112]. Hemmati et al. [113] compared the antiatherogenic effects of three medicinal plants C. sativus, Beta vulgaris L., and Ziziphus jujuba Mill. in diabetic rat models, where the three extracts possessed antiatherogenic activity, which is probably associated with the antioxidant capacities of the extracts.

5.2.2. Antiproliferative and Cytotoxic Activities. Saffron and its carotenoid constituents are chemopreventive in the growth of human malignant cells and animal models. Chermahini et al. [114] reported that saffron and its constituents could inhibit the synthesis of cellular DNA and RNA with no effect on protein synthesis in tumor cells. The antitumor effect of saffron and its ingredients is due to the free radicalscavenging effect, together with the interaction with topoisomerase II $[114,115]$.

Saffron exerted a protective effect against the toxicity of cisplatin when applied with the cysteine and vitamin E $[116,117]$. Saffron can potentiate the effect of other anticancer agents through the inhibition of colony formation and nucleic acid synthesis [116]. Saffron aqueous extract also reduced the dimethylnitrosamine- (DEN-) induced hepatic cancer through induction of apoptosis, inhibition of cell proliferation, oxidative stress, and inflammation [118]. Premkumar et al. [119] showed the antimutagenic and antioxidant potential of aqueous extract of saffron.

In mice, an aqueous extract of saffron has been found to prevent specific drugs (cisplatin, urethane, cyclophosphamide, and mitomycin C) that induced genotoxicity and oxidative stress besides increasing hepatic enzymes such as SOD, catalase (CAT), and nonenzymatic antioxidants [120]. The authors suggest that its chemopreventive role is observed because of its antioxidant activity and modulatory property during lipid peroxidation and detoxification.

\subsubsection{Neuroprotective Effects}

(1) Anticonvulsant Activity. In pentylenetetrazole- (PTZ-) and maximal electroshock seizure- (MES-) induced seizures in mice, Hosseinzadeh and Khosravan [121] indicated an anticonvulsant activity of aqueous and ethanolic extracts of C. sativus. Similar anticonvulsant activity was shown by safranal, contrary to that of crocin, which did not show any effect [16]. It is suggested that the anticonvulsant effect of safranal is mediated partly through GABA (A)-benzodiazepine receptor complex [122-126]. In addition, it is assumed that saffron's anticonvulsant and analgesic properties and its effects on morphine withdrawal might be due to an interaction between saffron, GABA, and opioid system [127]. Saffron did not significantly suppress PTZ-induced seizures at a dose of $200 \mathrm{mg} / \mathrm{kg}$ in rats [128].

(2) Neuroprotection in Neurodegenerative Diseases. Neurodegenerative diseases, such as Alzheimer's and Parkinson's diseases, are characterized by the presence of protein aggre- gates, inflammation, and oxidative stress in the central nervous system (CNS) [129]. A number of factors are involved in the onset of neurodegenerative diseases, which lead to the gradual deterioration of the health of the nervous system, with serious consequences on the quality of life of the patient with such a disease [130]. Although there are still no treatment solutions to restore nerve function in neurodegenerative diseases, more and more studies insist on several natural formulas that have been shown to have the effect of reducing symptoms and improving the quality of life of patients with neurodegenerative diseases. Alzheimer's disease is a neurodegenerative disease that causes disorders of memory, thinking, and behavior [131].

Saffron has been reported to inhibit the aggregation and deposition of amyloid $\beta(\mathrm{A} \beta)$ and thus prevent the shortterm memory problems characteristic of mild to moderate Alzheimer's disease. Inhibition of $\mathrm{A} \beta$ fibrillogenesis by methanol and water extract of $C$. sativus stigmas is doseand time-dependent [132-134]. Crocin was found more effective in preventing the toxic amyloid structures accumulation due to its amphiphilic properties [132]. On the other hand, trans-crocin 4 was more effective in Alzheimer's disease than dimethyl crocetin in inhibiting $A \beta$ fibrillogenesis through oxidation of the amyloid $\beta$-peptide fibrils [135]. Treatment with saffron extract could improve cognitive deficits induced by intracerebroventricular (ICV) injection of STZ in rats [136]. However, Khalili and Hamzeh [137] reported that the main component of saffron, crocin, is responsible for antagonizing the cognitive deficits caused by STZ-ICV in rats and can be used for treating the neurodegenerative diseases. Saffron had shown about 30\% inhibitory effect on acetylcholinesterase (AChE) activity, which can be another mechanism for treating Alzheimer's disease [138, 139].

Parkinson's disease is related to dopamine deficiency due to genetic factors or $\mathrm{Pb}$ intoxication and is characterized by the degeneration of neurons in the substantia nigra [140]. The accumulation of lead $(\mathrm{Pb})$ in the environment causes intoxication of the body, mainly affecting the CNS as it leads to structural and functional disruption of the CNS, and it may also develop Parkinson's disease. In a study performed by Tamegart et al. [141], the intraperitoneal injection of $\mathrm{Pb}$ caused a neurotoxic effect on the dopaminergic system and locomotor performance in Meriones shawi rats. The oral gavage of C. sativus $(50 \mathrm{mg} / \mathrm{kg}$ body weight) prevented $\mathrm{Pb}$-induced damages. Polyphenols such as quercetin and catechin have demonstrated $\mathrm{Fe}$ and $\mathrm{Zn}$ chelation activities. Thus, saffron may have a neuroprotective activity for neurodegenerative disorders, implying dopaminergic and noradrenergic injuries, especially heavy metal-induced Parkinson's disease.

Oxidative stress in the CNS is related with neurodegenerative diseases [142-144]. Crocetin could strengthen the antioxidant system and reduce thiobarbituric acid (TBARS), therefore inhibiting the effect of 6-hydroxydopamine, which is involved in inducing Parkinson's disease, and also decreased the utilization of dopamine [145]. In mice, saffron also showed effectiveness against MPTP- (1-methyl-4- 
phenyl-1,2,3,6-tetrahydropyridine-) induced Parkinson's disease, as pretreatment with saffron protected the dopaminergic cells in the substantia nigra pars compacta and retina [146].

(3) Antidepressant Effect. Saffron and its components possess antidepressant and anxiolytic effects [132]. Crocin (50$600 \mathrm{mg} / \mathrm{kg}$ ) reduced immobility time in rats in the forced swimming test, with the increase in climbing time [18]. Wang et al. [147] demonstrated that the petroleum ether and dichloromethane fractions C. cerebral sativus $\mathrm{L}$. corms have an antidepressant effect.

The aqueous and ethanolic extracts of $C$. sativus petal and stigma [148], as well as safranal and crocin, had shown antidepressant activity in mice [18]. In addition, kaempferol, a constituent of $C$. sativus petals, also reduced immobility behaviors in mice at 100 and $200 \mathrm{mg} / \mathrm{kg}$ and rats at a dose of $50 \mathrm{mg} / \mathrm{kg}$ [149]. The reduced time of immobility in rats and mice is usually due to the selective serotonin reuptake inhibitors such as fluoxetine, and this may be the mechanism by which $C$. sativus exerts its antidepressant effects [150].

(4) The Effects on Neurotoxicity and Neuronal Oxidative Damages. Neurotoxicity refers to disturbances or damage to the CNS by toxic substances and toxins that affect the nervous system are called neurotoxins $[52,151]$.

Safranal has neuroprotective effects on oxidative damage markers in hippocampal tissue in ischemic rats [152] and in hippocampal tissue in rats treated with quinolinic acid [153]. Safranal decreases extracellular content of the excitatory amino acids, glutamate, and aspartate in the hippocampus of anaesthetized rats treated with kainic acid [154].

Crocetin can inhibit early stages of apoptosis and induce angiogenesis at the subacute stage as depicted by vascular endothelial growth factor receptor-2 (VEGFR-2) and serum response factor (SRF) expression levels, so it exerts in vivo neuroprotective effects the brain [155]. It has been demonstrated that crocetin could potentiate the antioxidant capacity in the brain and prevents 6-hydroxydopamine-induced neurotoxicity [145].

Crocin has a unique, protective effect on ethanolinduced impairment of learning and memory [134].

Sahraeil et al. [156] reported that saffron ethanolic extract and crocin are effective against chronic stressinduced Wistar rats, through interaction with hormonal, metabolic, and behavioral changes induced by electric shock stress in rats. Saffron extract and crocin also improved spatial cognitive abilities following chronic cerebral hypoperfusion, most probably due to their antioxidant potential [157].

Crocin also potentiated SOD and GPx activity and decreased MDA concentration in the cortex of the ischemic stroke rat model [158]. In an ischemic stroke rat model, crocin increased antioxidant enzyme activity of SOD, CAT, and GPx and reduced MDA levels and lipid peroxidation [89]. In cerebral ischemia, crocin inhibited oxidizing reactions in mice microvessels in addition to modulating the ultrastructure of cortical microvascular endothelial cells (CMEC) [159]. Crocin and crocetin can inhibit the activated microglia by the repression of the NF- $\kappa$ B transcriptional activity [160].

Both saffron extract and crocin may improve learning and memory $[161,162]$ as both can prevent oxidative stress in the hippocampus [138]. The enhancing effect of saffron on memory is mediated by its effect on the cholinergic system $[162,163]$.

Saffron and its derivatives act as curative agents in focal ischemia [164], autoimmune encephalomyelitis in C57BL/6 mice, cerebral ischemia [158], hippocampal ischemia [165], and renal ischemia/reperfusion [166]. In the whole brain and cerebellum, saffron extract reversed aluminuminduced changes in monoamine oxidase A and B activity and lipid peroxidation levels [167]. The antioxidant potential of saffron may be responsible for attenuation in cerebral ischemia-induced oxidative damage in the rat hippocampus [152]. Ghazavi et al. [123] investigated ethanolic extracts of saffron in mice and observed an increase of antioxidant potential, increased level of glutathione and its dependent enzyme, and a suppression of the increased levels of MDA, glutamate, and aspartate.

(5) Effect on Brain Receptors. Saffron was reported to have a similar effect to $N$-methyl-D-aspartate (NMDA) receptor antagonists on conditioning place preference induced by morphine [168]. Furthermore, saffron analgesic effect may be reduced by NMDA receptor antagonists, which suggested an interaction of saffron with the glutamatergic system [169].

Crocin (200 and $600 \mathrm{mg} / \mathrm{kg}$ ) could inhibit the morphine withdrawal symptoms with no effect on the locomotor system $[170,171]$. The saffron extract reduced morphineinduced memory impairment [125] and prevented morphine-induced inhibition of spatial learning and memory in rats [172].

\subsubsection{Effects on Metabolisms}

(1) Hypolipidemic Effect. Premkumar et al. [173] showed that saffron and its constituents decreased triglycerides (TGs), TC, alkaline phosphatase (ALP), aspartate transaminase (AST), alanine aminotransferase (ALT), MDA, and GPx, reduced glutathione (GSH) and oxidized glutathione (GSSG) levels in serum, and provoked an increasing effect on SOD, CAT, fluorescence recovery after photobleaching (FRAP), and GSH values in the liver tissue. Saffron was more effective than its constituents to quench free radicals and ameliorate the damages of hyperlipidemia [174].

In diet-induced hyperlipidemic rats, crocin showed hypolipidemic effect by reducing serum TG, TC, and lowdensity lipoprotein (LDL), and very-low-density lipoprotein (VLDL) levels [175]. Hypoglyceridemic and hypocholesterolemic effects of crocin are also reported in quails kept on a hyperlipidemic diet $[110,176]$. Crocin selectively inhibits pancreatic lipase through competitive inhibition and provokes lipid decrease [175]. 
In quails, the reduction of serum TC, LDL, and TG was also prominent in treatment with crocetin [110]. Cousins and Miller [177] reported that intraperitoneal injection of crocetin was more effective in showing hypolipidemic effect compared to that of the subcutaneous injection. In hypolipidemic rats, crocetin, along with crocin, showed an inhibitory effect on the increased serum TG, TC, and LDL levels $[110,176]$.

(2) Antihyperglycemic Effect. Diabetes is the most common disease of the endocrine system and is triggered when the amount of insulin secreted in the body is not optimal or when peripheral cells do not respond to its action (insulin is a hormone that lowers blood glucose) [178, 179].

Crocus sativus aqueous extract has also been reported to have an effect on streptozotocin- (STZ-) induced diabetic rats [180]. Diabetic rats treated with aqueous saffron extract showed reduced expression of inflammatory cytokines in the abdominal aorta. Thus, saffron can be useful also in treating diabetes mellitus and its vascular complications.

Saffron, crocin, and safranal have shown antihyperglycemic activity in the alloxan-diabetic rats through increasing blood insulin levels and caused the renewal of $\beta$-cells in alloxan-diabetic rats with neither liver nor kidney toxicities [181-183]. Crocetin was able to increase insulin sensitivity, improving impaired glucose tolerance, hypertension due to a high-fructose diet, and dexamethasone injection in rats $[82,175,184]$. Also, crocetin reduced the palmitateinduced insulin sensitivity in the rat adipocytes [185]. Crocetin could also prevent diabetes-related vascular complications $[186,187]$.

5.3. Other Pharmacological Activities. Saffron and safranal extract show preventive effects in lung pathology during lung inflammation of sensitized guinea pigs [188]. Safranal was shown to significantly reduce the cough count in citric acid aerosol-induced irritation in guinea pigs [189]. This effect may be due to competitive antagonistic activity to histamine H1 receptors [190]. Safranal was tested on the murine model of asthma, where it increased airway hyperresponsiveness and, in lungs, reduced iNOS production, bronchial epithelial cell apoptosis, and Th2-type cytokine production [86].

Saffron showed an important role as a curative agent in visual impairment due its antioxidant potential [191]. Saffron as a dietary supplement prevents the effects of continuous light exposure that may cause photoreceptor and retinal stress in albino rats, besides maintaining both morphology and function by acting as an apoptotic regulator [192, 193]. In ischemic retinopathy, crocin facilitates the recovery of retina functioning [194]. In murine retina, oral administration of crocetin prevents NMDA-induced retinal damage by inhibiting the caspase pathway [195], and trans-crocetin showed an antagonistic effect of C. sativus extract on NMDA receptors [196]. Crocin $(50 \mathrm{mg} / \mathrm{kg})$ inhibits retinal ganglion cell (RGC) apoptosis after retinal ischemia/reperfusion injury via phosphatidylinositol 3-kinase/AKT (PI3K/AKT) signaling pathway and increasing $\mathrm{Bcl}-2 / \mathrm{BAX}$ ratio [197].
Crocin $(10 \mu \mathrm{M})$ could suppress tumor necrosis factor(TNF-) $\alpha$-induced expression of proapoptotic mRNA, which releases cytochrome c from mitochondria [198]. Moreover, crocetin can inhibit cell death of $\mathrm{H}_{2} \mathrm{O}_{2}$-induced RGC-5 and inhibit caspase- 3 and caspase- 9 activity [199].

Crocin analogues increased the blood flow in the retina and choroid and facilitated retinal function recovery [194].

Hosseinzadeh and Younesi [200] have shown that the ethanolic and aqueous extracts of saffron stigma could inhibit the acetic acid-induced writhing reflex in vivo and also had a curative effect on many complications such as the injury of the skeletal muscle of the lower limb [201] and reepithelialization of burn wounds [202].

The most relevant in vivo pharmacological studies with the major findings are shown in Table 2 and Figure 3.

\section{Clinical Studies}

Saffron extract ( $30 \mathrm{mg} / \mathrm{kg}$ for six weeks) had been reported to possess an antidepressant effect on patients similar to the effects of fluoxetine [215] and imipramine $100 \mathrm{mg} /$ day [15] (Table 3). Saffron extract at this dose was equally effective to fluoxetine ( $40 \mathrm{mg} /$ day) in improving depression symptoms in patients who were suffering from major depressive disorder (MDD) after undergoing percutaneous coronary intervention [216]. Basti et al. [217] also suggested its effectiveness in treating mild to moderate depression.

Lopresti et al. [218] designed a randomized, doubleblind, placebo-controlled study for 8 weeks on patients with 12-16 years of age, with mild to moderate anxiety or depressive symptoms. Tablets containing saffron extract (Affron ${ }^{\circledR}$, $14 \mathrm{mg}$ b.i.d.) were used. The treatment improved anxiety and depressive symptoms in youth with mild to moderate symptoms, at least from the perspective of the adolescent. However, these beneficial effects were not corroborated by parents.

Administration of saffron, $30 \mathrm{mg} /$ day, divided as $15 \mathrm{mg}$ two times daily, in subjects of 55 years and more, was as effective as donepezil for the treatment of mild to moderate Alzheimer's disease [219]. The saffron extract had similar side effects to those of donepezil but with less vomiting [219]. Another study performed on 46 patients with mild to moderate Alzheimer's disease had shown that saffron improved the cognitive functions [220].

In another study, $C$. sativus extract administration for 3 months significantly increased white blood cell count in patients who had normal white blood cell count compared to crocin or placebo. No significant change was observed in hematologic factors during the study [221].

\section{Safety and Toxicity Studies of Crocus Plants}

The analysis of medicinal plants for toxicity is fundamental for their reliable and safe use among consumers [224]. Several investigations should be carried out to assure the safety of bioactive compounds. Indeed, preclinical studies based on animal toxicity are fundamental steps to determine the toxicity of drugs. In this step, studies focused on the determination of lethal dose $\left(\mathrm{LD}_{50}\right)$ and the toxicity against several 


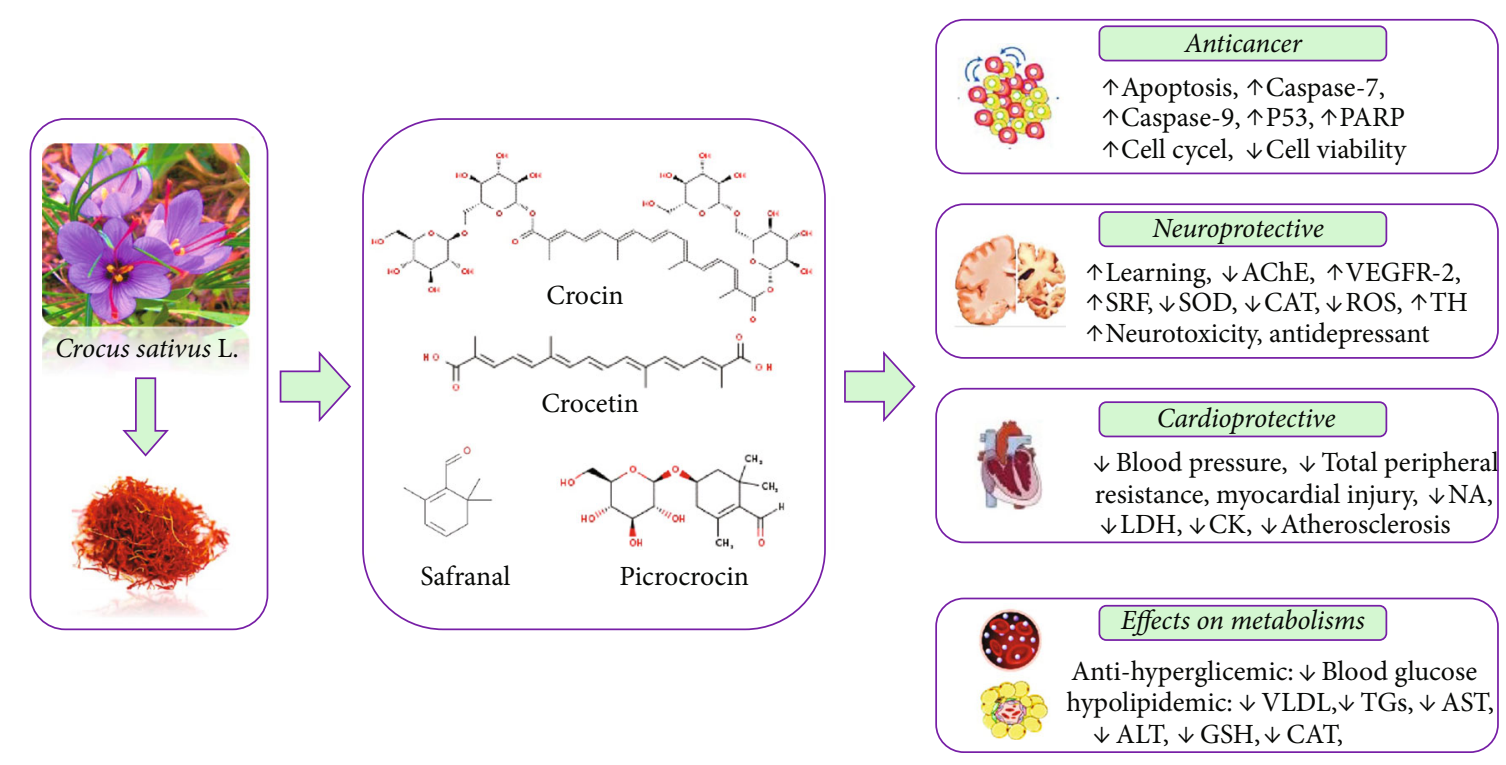

Figure 3: The role of Crocus plants' phytoconstituents in the pharmacotherapeutic management of various disorders and the possible molecular mechanisms of action. Abbreviations and symbols: $\uparrow$ increased, $\downarrow$ decreased, acetylcholinesterase (AChE), alkaline phosphatase $(A L P)$, aspartate transaminase $(A S T)$, catalase (CAT), creatine kinase (CK), glutathione (GSH), lactate dehydrogenase (LDH), noradrenaline (NA), poly (ADP-ribose) polymerase (PARP), reactive oxygen species (ROS), serum response factor (SRF), superoxide dismutase (SOD), tumor protein P53 (p53), tyrosine hydroxylase (TH), vascular endothelial growth factor receptor-2 (VEGFR-2), and very-low-density lipoprotein (VLDL).

organs (vital organs). Moreover, teratogenicity should also be evaluated in preclinical studies.

Preclinical toxicological studies of $C$. sativus and its bioactive cells were investigated by several studies in various animal models and different modes of administration.

Stigma and petal extracts of saffron exhibited moderated toxicological effects in mice using intraperitoneal administration. The $\mathrm{LD}_{50}$ values are 1.6 and $6 \mathrm{~g} / \mathrm{kg}$ for stigma and petal extracts, respectively [225]. However, the oral administration in mice of total saffron showed an $\mathrm{LD}_{50}$ of $4120 \mathrm{mg}$ / kg [225] (Table 4).

The ethanolic extract of saffron (stigma) showed significant effects using subacute doses in rats of the ethanolic extract $(0.35,0.7$, and $1.05 \mathrm{~g} / \mathrm{kg}$ i.p., for 2 weeks) that caused significant reductions in the hemoglobin $(\mathrm{Hb})$ and hematocrit (HCT) levels and total red blood cell (RBC) count [226]. Moreover, the total white blood cell (WBC) count showed significant dose-dependent increases in extracttreated rats. The ethanolic extract has also exhibited necessary increases of AST, ALT, urea, uric acid, and creatinine levels, which were dose-dependent. It was also shown that an ethanolic extract increased the levels of some enzymes involved in liver injury, in particular, ALT and AST [226]. Moreover, the histopathological findings reported that ethanolic extract induced mild to severe hepatic and renal injuries, thus supporting the biochemical analysis [226].

In another study also carried out by Mohajeri et al. [227], a total extract of saffron administered in rats $(0.35,0.70$, and $1.05 \mathrm{~g} / \mathrm{kg}$ i.p., for 2 weeks) showed some toxicity in the given doses and caused major hepatic and renal tissue damages. The aqueous extract of saffron administered intraperitoneally at $25-100 \mathrm{mg} / \mathrm{kg}$ increased survival in rats so that no mortality was observed at a dose of $10 \mathrm{mg} / \mathrm{kg}$ [228]. In another subacute study carried out by Karimi et al. [229], the aqueous extract of the petal $(1.2,2.4$, and $3.6 \mathrm{~g} / \mathrm{kg})$ and stigma $(0.16,0.32$, and $0.48 \mathrm{~g} / \mathrm{kg})$ of saffron administered intraperitoneally showed a significant decrease of body weight in rats. The biochemical analysis revealed that both extracts reduced the levels of $\mathrm{Hb}, \mathrm{HCT}$, and RBC counts. Moreover, both extracts produced anemia [229]. In another study, Khayatnouri et al. [230] have evaluated the effect of saffron on the spermatogenesis index in rats. The authors showed that saffron administered at $200 \mathrm{mg} / \mathrm{kg}$ of saffron for 28 days exhibited significantly decreased spermatogenesis index, including such indicators as repopulation index, tubular differentiation index, and spermatogenesis index [230].

The subchronic toxicity of saffron was also evaluated in several additional studies [231-235]. Modaghegh et al. [232] have tested the subchronic toxicity of saffron tablets on rats at 200 and $400 \mathrm{mg}$ per day for 1 week. The results showed that saffron might change some hematological and biochemical parameters. However, these adverse effects were within normal ranges because they had not altered clinical parameters [232]. Bahmani et al. [236] have tested the toxicity of the aqueous extract of saffron administered orally at 500,1000 , or $2000 \mathrm{mg} / \mathrm{kg} /$ day for three weeks to adult mice and neonates during lactation. The results did not show important toxicity $\left(\mathrm{LD}_{50}=4120 \mathrm{mg} / \mathrm{kg}\right)$ in mice. In addition, the histological analysis indicated that the aqueous extract of saffron did not have any toxic effects. The administration of saffron to BALB-c mice at 4000 and $5000 \mathrm{mg} / \mathrm{kg}$ following five weeks exposure significantly decreased $\mathrm{RBC}$ and $\mathrm{WBC}$ counts and Hb level [231]. Moreover, saffron caused kidney dysfunction revealed by the increase of blood urea nitrogen (BUN) and creatinine levels treated in animals. 
TABle 4: Toxicological studies of Crocus sativus L.

\begin{tabular}{|c|c|c|c|c|c|c|}
\hline $\begin{array}{l}\text { Extract/ } \\
\text { compound }\end{array}$ & Doses & $\begin{array}{l}\text { In vitro/ } \\
\text { in vivo }\end{array}$ & $\begin{array}{c}\text { Route of } \\
\text { administration }\end{array}$ & Model & Adverse effects & Ref. \\
\hline $\begin{array}{l}\text { Aqueous } \\
\text { extract }\end{array}$ & $1.2-2 \mathrm{~g} / \mathrm{bw}$ & In vivo & Intraperitoneal & Mice & Nausea, vomiting, diarrhea, bleeding & [234] \\
\hline $\begin{array}{l}\text { Aqueous } \\
\text { extract }\end{array}$ & $4 \mathrm{~g} / \mathrm{bw}$ daily & In vivo & Oral & Mice & Nontoxic & [235] \\
\hline $\begin{array}{l}\text { Aqueous } \\
\text { extract }\end{array}$ & $\mathrm{IC}_{50}=50-400 \mathrm{mg} / \mathrm{mL}$ & $\begin{array}{l}\text { In vitro } \\
\text { cytotoxic } \\
\text { assay }\end{array}$ & - & $\begin{array}{l}\text { CCD-18Lu } \\
\text { Human normal } \\
\text { lung cells }\end{array}$ & Noncytotoxic & {$[90]$} \\
\hline $\begin{array}{l}\text { Aqueous } \\
\text { extract }\end{array}$ & $\begin{array}{l}500,1000 \text {, and } 2000 \mathrm{mg} / \mathrm{kg} \\
\text { daily saffron, three weeks }\end{array}$ & In vivo & Oral & $\begin{array}{l}\text { Mice } \\
\text { Neonates mice } \\
\text { during lactation }\end{array}$ & $\begin{array}{c}\mathrm{LD}_{50}=4120 \mathrm{mg} / \mathrm{kg} \\
\uparrow \text { morphological changes in the kidney } \\
\text { of neonates }\end{array}$ & [236] \\
\hline $\begin{array}{l}\text { Aqueous } \\
\text { extract }\end{array}$ & 50,100 , and $200 \mathrm{mg} / \mathrm{kg}$ & In vivo & Intraperitoneal & $\begin{array}{c}\text { Rats } \\
\text { Diazinon- } \\
\text { induced toxicity }\end{array}$ & $\begin{array}{l}\text { Prevented the toxicity induced by } \\
\text { diazinon in rats }\end{array}$ & [238] \\
\hline $\begin{array}{l}\text { Ethanol } \\
\text { extract } \\
\text { stigmas }\end{array}$ & $0.35,0.70,1.05 \mathrm{~g} / \mathrm{kg}$ daily & In vivo & Intraperitoneal & $\begin{array}{l}\text { Rats } \\
\text { Subacute } \\
\text { toxicity }\end{array}$ & $\begin{array}{c}\downarrow \mathrm{Hb}, \downarrow \mathrm{HCT}, \downarrow \mathrm{RBC} \\
\uparrow \mathrm{AST}, \uparrow \mathrm{ALT}, \uparrow \text { urea, } \uparrow \text { uric acid } \\
\uparrow \text { creatinine } \uparrow \text { hepatic and renal tissue } \\
\text { injuries, dose-dependent }\end{array}$ & [227] \\
\hline $\begin{array}{l}\text { Ethanol } \\
\text { extract }\end{array}$ & $2 \mathrm{mg} / \mathrm{kg}$ of cisplatin & In vivo & Oral & $\begin{array}{c}\text { Mice } \\
\text { Cisplatin- } \\
\text { induced toxicity }\end{array}$ & $\begin{array}{l}\text { १life span of cisplatin-treated mice } \\
\text { almost threefold }\end{array}$ & [250] \\
\hline $\begin{array}{l}\text { Aqueous } \\
\text { extract }\end{array}$ & $25-100 \mathrm{mg} / \mathrm{kg}$ & In vivo & Intraperitoneal & $\begin{array}{l}\text { Rats } \\
\text { Acute and } \\
\text { subacute } \\
\text { toxicity }\end{array}$ & $\begin{array}{l}\uparrow \text { survival } \\
\text { No mortality at dose } 10 \mathrm{mg} / \mathrm{kg}\end{array}$ & [228] \\
\hline $\begin{array}{l}\text { Aqueous } \\
\text { extract }\end{array}$ & Several doses & In vivo & Oral & Rats & $21.42 \mathrm{~mL} / \mathrm{kg}$ & \multirow{4}{*}{ [251] } \\
\hline $\begin{array}{l}\text { Aqueous } \\
\text { extract }\end{array}$ & Several doses & In vivo & Intraperitoneal & Rats & $1.48 \mathrm{~mL} / \mathrm{kg}$ & \\
\hline $\begin{array}{l}\text { Aqueous } \\
\text { extract }\end{array}$ & Several doses & In vivo & Oral & Mice & $5.53 \mathrm{~mL} / \mathrm{kg}$ & \\
\hline $\begin{array}{l}\text { Aqueous } \\
\text { extract }\end{array}$ & Several doses & In vivo & Intraperitoneal & Mice & $3500 \mathrm{mg} / \mathrm{kg}$ & \\
\hline $\begin{array}{l}\text { Total } \\
\text { extract }\end{array}$ & $0.35,0.70$, and $1.05 \mathrm{~g} / \mathrm{kg}$ & In vivo & Intraperitoneal & Rats & $\begin{array}{c}\text { Hepatic, renal tissue damages anemia } \\
\qquad \downarrow \mathrm{Hb}, \downarrow \mathrm{HCT}, \downarrow \text { RBC }\end{array}$ & [226] \\
\hline Crocetin & $\begin{array}{c}10,25,50,100 \text {, and } \\
200 \mathrm{mM}\end{array}$ & In vitro & - & $\begin{array}{l}\text { Frog (Xenopus) } \\
\text { embryos }\end{array}$ & $\begin{array}{c}\text { Crocetin is a teratogen, but less potent } \\
\text { than ATRA }\end{array}$ & [252] \\
\hline Safranal & $0.1,0.5,1 \mathrm{~mL} / \mathrm{kg}$ & In vivo & Intraperitoneal & $\begin{array}{l}\text { Rats } \\
\text { Immunotoxin } \\
\text { effect }\end{array}$ & $\begin{array}{l}\text { Showed important toxicity than other } \\
\text { active constituents in saffron stigma }\end{array}$ & [247] \\
\hline Safranal & $1.2 \mathrm{~mL} / \mathrm{kg}$ & In vivo & Intraperitoneal & $\begin{array}{l}\text { Rats } \\
\text { Acute, subacute } \\
\text { toxicity }\end{array}$ & $\downarrow$ cytotoxicity & [228] \\
\hline Safranal & $1.2 \mathrm{~mL} / \mathrm{kg}$ & In vivo & Intraperitoneal & Mice & $\mathrm{LD}_{50}=1.48 \mathrm{~mL} / \mathrm{kg}$ & \multirow{6}{*}[225]{} \\
\hline Safranal & $1.2 \mathrm{~mL} / \mathrm{kg}$ & In vivo & Intraperitoneal & Mice & $\mathrm{LD}_{50}=1.88 \mathrm{~mL} / \mathrm{kg}$ & \\
\hline Safranal & $1.2 \mathrm{~mL} / \mathrm{kg}$ & In vivo & Intraperitoneal & Rats & $\mathrm{LD}_{50}=1.50 \mathrm{~mL} / \mathrm{kg}$ & \\
\hline Safranal & $1.2 \mathrm{~mL} / \mathrm{kg}$ & In vivo & Oral & Mice & $\mathrm{LD}_{50}=21.42 \mathrm{~mL} / \mathrm{kg}$ in & \\
\hline Safranal & $1.2 \mathrm{~mL} / \mathrm{kg}$ & In vivo & Oral & Mice & $\mathrm{LD}_{50}=11.42 \mathrm{~mL} / \mathrm{kg}$ & \\
\hline Safranal & $1.2 \mathrm{~mL} / \mathrm{kg}$ & In vivo & Oral & Rats & $\mathrm{LD}_{50}=5.53 \mathrm{~mL} / \mathrm{kg}$ & \\
\hline Crocin & $150-210 \mathrm{~g}$ & In vivo & $\begin{array}{l}\text { Oral, } \\
\text { intraperitoneal }\end{array}$ & $\begin{array}{l}\text { Mice } \\
\text { Rats }\end{array}$ & $\begin{array}{l}\uparrow \text { platelets, } \uparrow \text { creatinine } \\
\downarrow \text { food intake }\end{array}$ & [242] \\
\hline
\end{tabular}

Abbreviations and symbols: $\uparrow$ increase, $\downarrow$ decrease, ALT (alanine aminotransferase), AST (aspartate transaminase), ATRA (all-trans retinoic acid), Hb (hemoglobin), HCT (hematocrit), and RBC (red blood cell). 
Another study carried out by Amin et al. [237] showed that the aqueous saffron extract at lower doses $(25,50$, and $100 \mathrm{mg}$ / $\mathrm{kg}$ /day, administered intraperitoneally for 30 days) showed no toxicity on treated animals. Moreover, at these doses, this extract protects against ethylene glycol-induced calcium oxalate $(\mathrm{CaOx})$ nephrolithiasis in rats [237]. These findings indicate that saffron extracts possess toxicity at higher doses, while they could present protective effects at lower doses.

In a recent study carried out by Hosseinzadeh et al. [233], an aqueous extract of saffron stigmas, administered intraperitoneally at 20 and $80 \mathrm{mg} / \mathrm{kg}$, showed an important decrease of methyl methanesulfonate-induced DNA damage in mouse organs [233]. A study carried out by Hariri et al. [238] showed that aqueous extract administered intraperitoneally at 50,100, and $200 \mathrm{mg} / \mathrm{kg}$ prevented toxicity induced by diazinon in rats.

The teratogenic effect of aqueous extracts of saffron was investigated in mice by Zeynali et al. [239]. The administration of this extract at $0.8,0.4$, and $0.2 \%$ significantly reduced the tail length, biparietal diameter, placental diameter, and weight of the fetus during the gestational period. Moreover, the mortality rate and the mean number of the resorbed fetus were significantly increased in a dose-dependent manner [239]. Edamula et al. [240] have evaluated the prenatal developmental toxicity of saffron in male Wistar rats. The administration of the saffron extract at 1000, 250, and $50 \mathrm{mg} / \mathrm{kg}$ had no effects on gravid uterine weight, early and late resorptions, corpora lutea and implantation counts, and food intake [240]. Moreover, skeletal examinations have confirmed the absence of any malformation and biochemical examinations did not show effects in biochemical parameters [240].

Crocin is a major compound of saffron extract that has shown important pharmacological properties. The toxicity evaluation of this component was reported in some studies [241-244]. The acute toxicity of crocin on rats and mice was tested by Hosseinzadeh et al. [242]. The results showed that oral and intraperitoneally administration of crocin at $3 \mathrm{~g} / \mathrm{kg}$ over 2 days did not cause mortality. Moreover, biochemical, hematological, and pathological investigations revealed that crocin did not cause damage to any major organ in the body [242]. Indeed, at $180 \mathrm{mg} / \mathrm{kg} /$ day for 21 days, the intraperitoneal administration of crocin increased platelets and creatinine levels. Moreover, the same dose reduced weight, food intake, and alveolar size. Besides, at $90 \mathrm{mg} / \mathrm{kg}$, crocin decreased the levels of albumin and ALP with a significant increase in LDL level [242].

On the other hand, it was previously reported by Wang et al. [241] that crocin induced important black pigmentation of the liver and acute hepatic damage associated with discoloration. These damages were observed only at a higher dosage (100 mg/kg for 2 weeks). However, crocin at $50 \mathrm{mg} /$ $\mathrm{kg} /$ day (for 8 days) did not affect hepatic function [241]. Subacute toxicity of crocin on rats was examined in another study by Taheri et al. [243]. The results showed that the administration of crocin at 50,100, and $200 \mathrm{mg} / \mathrm{kg}$ did not show negative effects on biochemical parameters such as ALT, AST, ALP, urea, uric acid, creatinine, MDA, and GSH. Moreover, no significant toxicity was observed using histopathological investigations [243].
On the other hand, the teratogenic effect of crocin was investigated by Moallem et al. [244] in mice. In this work, the intraperitoneal administration of crocin at $200 \mathrm{mg} / \mathrm{kg}$ and $600 \mathrm{mg} / \mathrm{kg}$ showed a disruption in skeletal formation. Moreover, at the same doses, crocin affected weight, length, growth, mandible, and calvaria of fetuses indicated by the examination of maternal and fetal factors [244].

The acute toxicity of safranal (main compound of saffron) was evaluated in male mice, female mice, and male Wistar rats. The intraperitoneal administration of safranal showed significant toxicity in male mice $\left(\mathrm{LD}_{50}=1.48 \mathrm{~mL} / \mathrm{kg}\right)$, female mice $\left(\mathrm{LD}_{50}=1.88 \mathrm{~mL} / \mathrm{kg}\right)$, and male Wistar rats $\left(\mathrm{LD}_{50}=1.50 \mathrm{~mL} / \mathrm{kg}\right)$. However, in oral administration of safranal, $\mathrm{LD}_{50}$ values were $21.42,11.42$, and $5.53 \mathrm{~mL} / \mathrm{kg}$ in male mice, female mice, and male rats, respectively [225]. In this study, the authors suggested that the significant difference in $\mathrm{LD}_{50}$ values after intraperitoneal and oral administration is due to first-pass metabolism and lower absorption after oral exposure [225].

In another study, the subacute toxicity was evaluated in mice and rats. Safranal was administered orally at $0.1,0.25$, and $0.5 \mathrm{~mL} / \mathrm{kg} /$ day over 21 days [245]. Safranal induced significant decreases in several hematological parameters such as RBC counts, HCT, Hb, and platelets. Moreover, safranal reduced some biochemical factors, including TC, TG, and ALP. Also, no noticeable heart, liver, or spleen lesions were observed after pathological examinations [246]. On the other hand, Riahi-Zanjani et al. [247] have tested the immunotoxic effect of safranal on cellular and humoral cells of the immune system in mice. The results of this work showed that the intraperitoneal administration of safranal at 0.1 , 0.5 , and $1 \mathrm{~mL} / \mathrm{kg}$ within 3 weeks days (5 days/week) did not show any significant toxicity on immune system cells [247]. In other studies carried out by Moallem et al. [244], safranal administered at 0.075 and $0.225 \mathrm{~mL} / \mathrm{kg}$ dysregulated skeletal formation and affected maternal and fetal factors such as weight, length, and growth [244].

The clinical investigations of saffron and its derivatives have also been reported [232, 248, 249]. The examination of saffron safety in healthy volunteers at 200 and $400 \mathrm{mg}$ within 7 days by Modaghegh et al. [232] showed a decrease in arterial pressures, and standing systolic BPs were decreased in persons who received $400 \mathrm{mg}$ [232]. Moreover, at the same concentrations (200 and $400 \mathrm{mg}$ ), saffron was found to be a safe drug on the coagulation system [248]. Mohamadpour et al. [249] also investigated the clinical toxicity of crocin in healthy volunteers. In this study, crocin was examined at $20 \mathrm{mg}$ using a randomized, double-blind, placebo-controlled trial. Administrations of crocin tablets partially decreased thromboplastin time, amylase, and mixed WBC (monocytes, basophils, and eosinophils), which showed that crocin is a relatively safe product [249].

\section{Discussion}

Crocus plants have been traditionally used for several purposes (e.g., reduce bruises, promote blood circulation, anxiolytic, antitumor, antihyperglycemic, etc.) $[147,181$, 253-256]. Crocus sativus is listed in the pharmacopoeias of 
several realms such as Europe, the United Kingdom, Japan, and China [253, 257-259], as well as in other national or local standards.

Crocus plants have undergone comprehensive validation, including phytochemical profiling and determination of targeted biological activities. Saffron is a valuable plant whose main components include safranal, crocetin, crocin, and picrocrocin.

It has been shown in bioavailability tests that when administered orally, crocins are not resorbed as such, but only after an intestinal deglycosylation, after which they reach the bloodstream, being able to cross the blood-brain barrier. This is also the reason why a process for concentrating hydroalcoholic extracts has been developed, when a product with more than $90 \%$ crocin 1 is finally obtained, which, being subjected to an enzymatic transformation treatment with $\beta$-glucosidase, provides the active metabolite, trans-crocetin, with a concentration of $70 \%$ [260].

Both in vivo and in vitro studies have shown that much of the biological effectiveness of saffron can be attributed to its antioxidant potential resulting from the synergistic antioxidant capacity of its bioactive ingredients [261]. The antioxidant activity of $C$. sativus is mainly attributable to its antioxidant active constituents such as safranal, crocin, and crocetin [83].

The radical-scavenging activity of Crocus plant extracts is associated with its anti-inflammatory activity. Crocin and safranal showed anti-inflammatory and antinociceptive effects in the carrageenan model of inflammation with comparable effect to diclofenac [214]. The saffron extract was reported to possess a more significant radical-scavenging activity than carrot and tomato extracts [135]. Crocin and safranal mediate their antioxidant activities by modulating redox status in human plasma [87], mice [204], and primary hepatocytes of rats [262]. Saffron and crocin ameliorate the effects of Vipera russelli venom-induced oxidative stress and hematological alterations in adult mice [173, 263].

Crocetin, as a strong antioxidant compound, was demonstrated to inhibit lipid peroxidation, increase the activity of glutathione $S$-transferase (GST), GPx, CAT, and SOD, decrease damage marker enzymes such as aryl hydrocarbon hydroxylase $(\mathrm{AHH}), \mathrm{LDH}, \boldsymbol{\gamma}$-glutamyl transferase (GGT), and adenosine deaminase (ADA) in rat liver tissues, inhibit proliferation of lung cancer cells $[174,264]$, reduce ROSinduced lipid peroxidation in primary hepatocytes of rats [262], and reduce the levels of oxidized LDL [111]. Crocetin decreased the expression of TNF- $\alpha$, interleukin- $1 \beta$, and induced iNOS in the liver of the hemorrhagic shock model [265]. Crocetin also decreased the indomethacin-induced rise in glutathione in nondiabetic and diabetic rats [266] and reduced ROS generated by $\mathrm{B} \alpha \mathrm{P}$ in mice [204] and angiotensin II-induced ROS [126].

Crocetin was found to be more effective than dimethyl crocetin and safranal as an anticancer and chemopreventive agent [264]. This may be due to the free hydroxyl moiety of the carboxylic group in crocetin that makes it potent for proton donor, thus more reactive to free radicals [203]. Saffron extracts administered orally or topically reduced the in vivo incidence of induced cancers, inhibiting tumor growth rate and prolonging the life of test animals. Furthermore, the toxicity of cytostatic drugs (i.e., cisplatin) has been reduced in experimental models in animals.

The cardioprotective effect of crocetin against norepinephrine- (NE-) induced cardiac hypertrophy has been related with its modulation effects of endogenous antioxidant enzymatic activities [267]. However, the synergism between all these bioactive components significantly potentiates the antioxidant capacity of saffron [264].

Aqueous and ethanolic saffron extracts were tested, along with saffron and crocin, for antidepressant effects in mice using the forced swimming test. All proved to have antidepressant action, and the saffron and crocin content of the extracts administered is reflected in the recorded result. Crocin probably works by inhibiting dopamine and NE reuptake, while safranal inhibits serotonin reuptake at the synapse.

Saffron plays an important role in the food industry and home cooking, both as a preservative and a dye for foods and beverages [268].

The antibacterial activity of aqueous extracts of saffron stigmas was observed against S. aureus, Enterococcus faecalis, and E. coli by Cenci-Goga et al. [72]. It was concluded that stigmas of $C$. sativus have enough antimicrobial agents to exhibit preservative function in foods depending on its compatibility with the product [72]. Saffron, which contains carotenoids (mainly crocin), shows antiseptic activity as its alcoholic compounds can easily alter the cell protein nature and impair the permeability of the cell membranes [71]. In one more study, it was reported that the presence of antimicrobial agents in saffron stigma suppressed microbial growth. Cosano et al. [269], who considered several saffron products from different producing countries (Spain, Iran, Italy, Greece, and Morocco), showed saffron to be a safe additive having neither microbial load nor health risk to foods after addition when there are no other foodpreservation methods [269]. A research carried out by Pintado et al. [270] introduced safranal and crocin as biologically active compounds responsible for bacterial growth inhibition. They reported that safranal and crocin could significantly preserve foods against Salmonella, E. coli, and S. aureus when added to foodstuff [270]. Abbasvali et al. [271] reported that an aqueous extract of saffron petals at a concentration of $5 \mathrm{mg} / \mathrm{mL}$ had strong antibacterial effects against $S$. aureus. They studied the preservation effects of petal extracts on the shelf life of shrimp and observed that aqueous petal extracts prolonged the shelf life of shrimp from 3 to 9 days. The influence of phenolic components on bacterial cell walls as well as chelation of metal ions necessary for microbial growth was deemed to be the main food-preservation factor. They concluded that aqueous saffron petal extracts contain significantly more phenolic compounds compared to either ethanolic or methanolic extracts and consequently showed stronger antimicrobial effects.

Another example of using saffron extract as a food preservative was reported by Aktypis et al. [272] in which saffron was added to ovine cheese. They found that saffron, as a natural additive, owed a mild reduction in bacterial growth over a month (30 days) after production weight $n$ 
is being kept at $4^{\circ} \mathrm{C}$. Saffron not only made the food functional but also imparted a pleasant flavor to the product [272]. Phenolics, especially flavonoids, usually have strong antioxidant capacities, and thus, herbs rich in them are frequently used as antioxidant food supplements [138, 261]. Cosano et al. [269], who considered several saffron products from different producing countries (Spain, Iran, Italy, Greece, and Morocco), showed saffron to be a safe additive having neither microbial load nor health risk to foods after addition when there are no other food-preservation methods [269].

The limitations are represented by the toxicological evaluation of Crocus species which has not been widely studied, and the majority of toxicity tests have focused mainly on $C$. sativus and its major compounds. Toxicological investigations of saffron were carried out only in several studies $[225,227,228,232,236,238,251]$. The toxicological findings for saffron are not uniform and have some variability depending on plant parts used and experimental models.

To summarize, saffron is a valuable additive containing biologically active compounds which can add functional properties to food products. Saffron powder as well as extract can dramatically influence microbial growth when added to foods and served to preserve foods from spoilage. It should be noted that using saffron does have some limitations, such as an unacceptable flavor of food when used in large enough quantities to ensure high levels of preservation. Combination of saffron with other preservatives (e.g., salt and acid) or merging with other food-preservation methods (freezing, thermal processing) has been proposed to solve this limitation.

\section{Overall Conclusions and Future Perspectives}

Saffron has been used in several traditional medicinal systems against several diseases, including asthma, cardiovascular disease, depression, digestive ailments, and insomnia.

The Crocus plants, C. sativus being the most studied, comprise a matrix of phytochemicals promising for biotechnological and pharmaceutical purposes. The pharmaceutical and biotechnological industries are continuously searching for potential functional components in the plant kingdom, and there is excellent economic interest if it is determined to be more economical to obtain these compounds by extracting them from the plants as opposed to their chemical synthesis. In the case of saffron, the extraction of its phytocomponents may be limited by economic aspects. However, the study of the phytochemical profile of saffron and the study of the biological activities of these components may lead to the discovery of new mimetics of these compounds or improvements in the laboratory syntheses. Advances in plant research have been realized to develop saffron with better profiles for the food industry but not for pharmaceutical and biotechnological industries. Crocins, picrocrocin, and safranal are relevant in terms of aroma and taste, but as it has been exposed in this review, these components also possess interesting biological properties. A small number of clinical trials have been performed using saffron as a potential agent for anti-Alzheimer's, antidepressant, and anti- schizophrenia effects. Further efforts are needed to study the other biological effects shown in in vitro and in vivo studies in well-designed trials in humans.

\section{Abbreviations}

AChE: Acetylcholinesterase

ADA: $\quad$ Adenosine deaminase

AHH: $\quad$ Aryl hydrocarbon hydroxylase

ALP: $\quad$ Alkaline phosphatase

ALT: $\quad$ Alanine aminotransferase

AST: $\quad$ Aspartate transaminase

AV: $\quad$ Atrioventricular

A $\beta$ : $\quad$ Amyloid $\beta$

BHT: $\quad$ Butyl hydroxyl toluene

BP: $\quad$ Blood pressure

BUN: Blood urea nitrogen

CaOx: Calcium oxalate

CAT: Catalase

CK: $\quad$ Creatine kinase

CMEC: Cortical microvascular endothelial cells

CNS: Central nervous system

DAD: Diode-array detection

DEN: Dimethylnitrosamine

DOCA: Desoxycorticosterone acetate

DPPH, 2: 2-Diphenyl-1-picryl-hydrazyl-hydrate

ESI: $\quad$ Electrospray ionization

FRAP: $\quad$ Fluorescence recovery after photobleaching

GC: Gas chromatography

GGT: $\quad \gamma$-Glutamyl transferase

GPx: $\quad$ Glutathione peroxidase

GSH: $\quad$ Reduced glutathione

GSSG: Oxidized glutathione

GST: $\quad$ Glutathione S-transferase

$\mathrm{Hb}$ : Hemoglobin

HCT: Hematocrit

HPLC: Performance liquid chromatography

HPTLC: High-performance thin-layer chromatography

ICV: Intracerebroventricular

iNOS: $\quad$ Induced nitric oxide synthase

ISO: Isoproterenol

LC: $\quad$ Liquid chromatography

LDH: $\quad$ Lactate dehydrogenase

LDL: $\quad$ Low-density lipoprotein

MDA: $\quad$ Malondialdehyde

MDD: $\quad$ Major depressive disorder

MES: $\quad$ Maximal electroshock seizure

MMP: $\quad$ Matrix metalloproteinase

MPTP: 1-Methyl-4-phenyl-1,2,3,6-tetrahydropyridine

MS: $\quad$ Mass spectrometry

NE: $\quad$ Norepinephrine

NF- $\kappa$ B: $\quad$ Nuclear factor $\kappa \mathrm{B}$

NMDA: N-Methyl-D-aspartate

NMR: $\quad$ Nuclear magnetic resonance

NO: $\quad$ Nitric oxide production

NS: $\quad$ Nervous system

PARP: $\quad$ Poly (ADP-ribose) polymerase

PI3K/AKT: Phosphatidylinositol 3-kinase

PTZ: $\quad$ Pentylenetetrazole 


$\begin{array}{ll}\text { RBC: } & \text { Red blood cell } \\ \text { RGCs: } & \text { Retinal ganglion cells } \\ \text { ROS: } & \text { Reactive oxygen species } \\ \text { SOD: } & \text { Superoxide dismutase } \\ \text { SRF: } & \text { Serum response factor } \\ \text { TBARS: } & \text { Thiobarbituric acid } \\ \text { TC: } & \text { Total cholesterol } \\ \text { TG: } & \text { Triglyceride } \\ \text { TLC: } & \text { Thin-layer chromatography } \\ \text { TNF- } \alpha: & \text { Tumor necrosis factor- } \alpha \\ \text { VCAM-1: } & \text { Vascular cell adhesion molecule-1 } \\ \text { VEGFR-2: } & \text { Vascular endothelial growth factor receptor-2 } \\ \text { VLDL: } & \text { Very-low-density lipoprotein } \\ \text { WBC: } & \text { White blood cells. }\end{array}$

\section{Data Availability}

All the data used to support the findings of this study are included within the article.

\section{Conflicts of Interest}

The authors declare that the research was conducted in the absence of any commercial or financial relationships that could be construed as a potential conflict of interest.

\section{Authors' Contributions}

All authors made a significant contribution to the work reported, whether that is in the conception, study design, execution, acquisition of data, analysis, and interpretation, or in all these areas, that is revising or critically reviewing the article, giving final approval of the version to be published, agreeing on the journal to which the article has been submitted, and confirming to be accountable for all aspects of the work.

\section{Supplementary Materials}

Table S1: phytoconstituents of Crocus species detected by various techniques. Table S2: phytoconstituents of Crocus species detected by gas chromatography coupled to mass spectrometry (GC-MS). The Supplementary Material for this article can be found online. (Supplementary Materials)

\section{References}

[1] O. Ahrazem, A. Rubio-Moraga, S. G. Nebauer, R. V. Molina, and L. Gomez-Gomez, "Saffron: its phytochemistry, developmental processes, and biotechnological prospects," Journal of Agricultural and Food Chemistry, vol. 63, pp. 8751-8764, 2015.

[2] J. A. Fernández, O. Santana, J. L. Guardiola et al., "The world saffron and Crocus collection: strategies for establishment, management, characterisation and utilisation," Genetic Resources and Crop Evolution, vol. 58, pp. 125-137, 2011.

[3] R. Dewan, "Bronze age flower power: the Minoan use and social significance of saffron and Crocus flowers," Chronica, vol. 5, pp. 42-55, 2015.

[4] L. Mohtashami, M. S. Amiri, M. Ramezani, S. A. Emami, and J. Simal-Gandara, "The genus Crocus L.: A review of ethnobo- tanical uses, phytochemistry and pharmacology," Industrial Crops and Products, vol. 171, p. 113923, 2021.

[5] S. Z. Bathaie and S. Z. Mousavi, "New applications and mechanisms of action of saffron and its important ingredients," Critical Reviews in Food Science and Nutrition, vol. 50, pp. 761-786, 2010.

[6] Y. Deng, Z. G. Guo, Z. L. Zeng, and Z. Wang, "Studies on the pharmacological effects of saffron (Crocus sativus L.)-a review," Zhongguo Zhong yao za zhi = Zhongguo zhongyao zazhi $=$ China journal of Chinese materia medica, vol. 27, no. 8, pp. 565-568, 2002.

[7] G. Betti and M. Schmidt, "Valorization of saffron (Crocus sativus)," Acta horticulture, vol. 739, pp. 397-403, 2013.

[8] B. K. Bhargava, "Medicinal uses and pharmacological properties of Crocus sativus Linn (saffron)," International Journal of Pharmacy and Pharmaceutical Sciences, vol. 3, pp. 22-26, 2011.

[9] M. Moghaddasi, "Saffron chemicals and medicine usage," Journal of Medicinal Plant Research: Planta Medica, vol. 4, no. 6, pp. 427-430, 2010.

[10] T. S. Cid-Pérez, G. V. Nevárez-Moorillón, C. E. OchoaVelasco, A. R. Navarro-Cruz, P. Hernández-Carranza, and R. Avila-Sosa, "The relation between drying conditions and the development of volatile compounds in saffron (Crocus sativus)," Molecules, vol. 26, no. 22, p. 6954, 2021.

[11] K. Zeka, K. C. Ruparelia, M. A. Continenza, D. Stagos, F. Veglio, and R. R. J. Arroo, "Petals of Crocus sativus L. as a potential source of the antioxidants crocin and kaempferol," Fitoterapia, vol. 107, pp. 128-134, 2015.

[12] A. Trapero, O. Ahrazem, A. Rubio-Moraga, M. L. Jimeno, M. D. Gomez, and L. Gomez-Gomez, "Characterization of a glucosyltransferase enzyme involved in the formation of kaempferol and quercetin sophorosides in Crocus sativus," Plant Physiology, vol. 159, pp. 1335-1354, 2012.

[13] F. N. Lamari, V. Papasotiropoulos, D. Tsiris et al., "Phytochemical and genetic characterization of styles of wild Crocus species from the island of Crete, Greece and comparison to those of cultivated C. sativus," Fitoterapia, vol. 130, pp. 225-233, 2018.

[14] O. Mykhailenko, I. Bezruk, L. Ivanauskas, and V. Georgiyants, "Comparative analysis of apocarotenoids and phenolic constituents of Crocus sativus stigmas from 11 countries: ecological impact," Archiv der Pharmazie, p. e2100468, 2022.

[15] S. Akhondzadeh, H. Fallah-Pour, K. Afkham, A. H. Jamshidi, and F. Khalighi-Cigaroudi, "Comparison of Crocus sativus L. and imipramine in the treatment of mild to moderate depression: a pilot double-blind randomized trial [ISRCTN45683816]," BMC Complementary and Alternative Medicine, vol. 4, no. 1, 2004.

[16] H. Hosseinzadeh and F. Talebzadeh, "Anticonvulsant evaluation of safranal and crocin from Crocus sativus in mice," Fitoterapia, vol. 76, pp. 722-724, 2005.

[17] H. Hosseinzadeh and H. R. Sadeghnia, "Protective effect of safranal on pentylenetetrazol-induced seizures in the rat: involvement of GABAergic and opioids systems," Phytomedicine, vol. 14, pp. 256-262, 2007.

[18] H. Hosseinzadeh, G. Karimi, and M. Niapoor, "Antidepressant effect of Crocus sativus L. stigma extracts and their constituents, crocin and safranal, in mice," Acta Horticulturae, vol. 650, pp. 435-445, 2004. 
[19] "Plant List, T," http://www.theplantlist.org/.

[20] M. Heinrich, G. Appendino, T. Efferth et al., "Best practice in research - overcoming common challenges in phytopharmacological research," Journal of Ethnopharmacology, vol. 246, p. 112230, 2020.

[21] A. R. Krishnan, J. Mathew, S. A. Salam, V. Jiju, and A. Elessy, "A review on saffron as an alternative therapy in medicine and dermatology," European Journal of Pharmaceutical and Medical Research, vol. 4, pp. 283-286, 2017.

[22] M. Sheidai, M. Tabasi, M. Mehrabian, F. Koohdar, S. Ghasemzadeh-Baraki, and Z. Noormohammadi, "Species delimitation and relationship in Crocus L. (Iridaceae)," Acta Botanica Croatica, vol. 77, pp. 10-17, 2018.

[23] T. Aburjai, M. Hudaib, R. Tayyem, M. Yousef, and M. Qishawi, "Ethnopharmacological survey of medicinal herbs in Jordan, the Ajloun Heights region," Journal of Ethnopharmacology, vol. 110, pp. 294-304, 2007.

[24] M. Asadi, "Antioxidant and antimicrobial activities in the different extracts of Caspian saffron, Crocus caspius Fisch \& C. A. Mey. ex Hohen," Caspian Journal of Environmental Sciences, vol. 14, pp. 331-338, 2016.

[25] Z. Demeter, G. Suranyi, V. A. Molnar et al., "Somatic embryogenesis and regeneration from shoot primordia of Crocus heuffelianus," Plant Cell, Tissue and Organ Culture, vol. 100, pp. 349-353, 2010.

[26] N. Jivad, N. Zare-Hassanabadi, and M. Azizi, "Effect of combination of honey, saffron (Crocus sativus L.) and sedge (Cyperus rotundus L.) on cognitive dysfunction in patients with Alzheimer's disease," Advanced Herbal Medicine, vol. 1, pp. 11-16, 2015.

[27] A. Pieroni, "Medicinal plants and food medicines in the folk traditions of the upper Lucca Province, Italy," Journal of Ethnopharmacology, vol. 70, no. 3, pp. 235-273, 2000.

[28] A. Bilal, A. H. Wani, A. Khan, R. Hamza, and F. A. Mohidin, "Saffron: a repository of medicinal properties," Journal of Medicinal Plant Research, vol. 5, pp. 2131-2135, 2011.

[29] Z. A. Shah, R. Mir, J. M. Matoo, M. A. Dar, and M. A. Beigh, "Medicinal importance of saffron: a review," Journal of Pharmacognosy and Phytochemistry, vol. 6, pp. 24752478, 2017.

[30] S. Z. Mousavi and S. Z. Bathaie, "Historical uses of saffron: identifying potential new avenues for modern research," Avicenna Journal of Phytomedicine, vol. 1, pp. 57-66, 2011.

[31] I. Hasan, A. H. Ansari, A. M. Sherwani, and M. Zulkifle, "The incredible health benefits of saffron: a review," Journal of Pharmacy Research, vol. 4, pp. 2156-2158, 2011.

[32] A. H. Rahmani, A. A. Khan, and Y. H. Aldebasi, "Saffron (Crocus sativus) and its active ingredients: role in the prevention and treatment of disease," Pharmacognosy Journal, vol. 9, pp. 873-879, 2017.

[33] A. A. D'Archivio and M. A. Maggi, "Geographical identification of saffron (Crocus sativus L.) by linear discriminant analysis applied to the UV-visible spectra of aqueous extracts," Food Chemistry, vol. 219, pp. 408-413, 2017.

[34] M. Mashmoul, A. Azlan, H. Khaza'ai, B. N. Yusof, and S. M. Noor, "Saffron: a natural potent antioxidant as a promising anti-obesity drug," Antioxidants, vol. 2, pp. 293-308, 2013.

[35] M. A. Bonet and J. Valles, "Ethnobotany of Montseny biosphere reserve (Catalonia, Iberian Peninsula): plants used in veterinary medicine," Journal of Ethnopharmacology, vol. 110, pp. 130-147, 2007.
[36] L. Maggi, M. Carmona, S. D. Kelly, N. Marigheto, and G. L. Alonso, "Geographical origin differentiation of saffron spice (Crocus sativus L. stigmas) - preliminary investigation using chemical and multi-element $(\mathrm{H}, \mathrm{C}, \mathrm{N})$ stable isotope analysis," Food Chemistry, vol. 128, pp. 543-548, 2011.

[37] M. Tsimidou and P. A. Tarantilis, "Special issue "Saffron (Crocus sativus L.): omics and other techniques in authenticity, quality, and Bioactivity Studies"," Molecules, vol. 22, 2016.

[38] R. Rocchi, M. Mascini, M. Sergi, D. Compagnone, D. Mastrocola, and P. Pittia, "Crocins pattern in saffron detected by UHPLC-MS/MS as marker of quality, process and traceability," Food Chemistry, vol. 264, pp. 241-249, 2018.

[39] S. Patel, M. Sarwat, and T. H. Khan, "Mechanism behind the anti-tumour potential of saffron (Crocus sativus L.): the molecular perspective," Critical Reviews in Oncology/Hematology, vol. 115, pp. 27-35, 2017.

[40] F. I. Abdullaev, "Cancer chemopreventive and tumoricidal properties of saffron (Crocus sativus L.)," Experimental Biology and Medicine (Maywood, N.J.), vol. 227, no. 1, pp. 2025, 2002.

[41] A. R. Gohari, S. Saeidnia, and M. K. Mahmoodabadi, “An overview on saffron, phytochemicals, and medicinal properties," Pharmacognosy Reviews, vol. 7, pp. 61-66, 2013.

[42] R. Srivastava, H. Ahmed, R. K. Dixit, Dharamveer, and S. A. Saraf, "Crocus sativus L.: a comprehensive review," Pharmacognosy Reviews, vol. 4, no. 8, pp. 200-208, 2010.

[43] A. M. Sánchez, M. Carmona, C. P. del Campo, and G. L. Alonso, "Solid-phase extraction for picrocrocin determination in the quality control of saffron spice (Crocus sativus L.)," Food Chemistry, vol. 116, pp. 792-798, 2009.

[44] M. V. Garcia-Rodriguez, J. Serrano-Diaz, P. A. Tarantilis, H. Lopez-Corcoles, M. Carmona, and G. L. Alonso, "Determination of saffron quality by high-performance liquid chromatography," Journal of Agricultural and Food Chemistry, vol. 62, pp. 8068-8074, 2014.

[45] P. Winterhalter and R. Rouseff, "Carotenoid-derived aroma compounds: an introduction," ACS Symposium Series, vol. 802, pp. 1-17, 2001.

[46] A. N. Assimopoulou, Z. Sinakos, and V. P. Papageorgiou, "Radical scavenging activity of Crocus sativus L. extract and its bioactive constituents," Phytotherapy research: PTR, vol. 19, pp. 997-1000, 2005.

[47] H. Caballero-Ortega, R. Pereda-Miranda, L. Riverón-Negrete et al., "Chemical composition of saffron (Crocus sativus L.) from four countries," Acta Horticulturae, no. 650, pp. 321326, 2004.

[48] F. Bouvier, C. Suire, J. Mutterer, and B. Camara, "Oxidative remodeling of chromoplast carotenoids: identification of the carotenoid dioxygenase CsCCD and CsZCD genes involved in Crocus secondary metabolite biogenesis," The Plant Cell, vol. 15, pp. 47-62, 2003.

[49] A. R. Moraga, P. F. Nohales, J. A. Perez, and L. GomezGomez, "Glucosylation of the saffron apocarotenoid crocetin by a glucosyltransferase isolated from Crocus sativus stigmas," Planta, vol. 219, no. 6, pp. 955-966, 2004.

[50] P. Winterhalter and M. Straubinger, "Saffron-renewed interest in an ancient spice," Food Reviews International, vol. 16, pp. 39-59, 2000.

[51] H. Rajabi, M. Ghorbani, S. M. Jafari, A. Sadeghi Mahoonak, and G. Rajabzadeh, "Retention of saffron bioactive components by spray drying encapsulation using maltodextrin, 
gum Arabic and gelatin as wall materials," Food Hydrocolloids, vol. 51, pp. 327-337, 2015.

[52] B. Salehi, S. Sestito, S. Rapposelli et al., "Epibatidine: a promising natural alkaloid in health," Biomolecules, vol. 9, p. 10, 2019.

[53] A. Benkhaled, A. Senator, A. Boudjelal et al., "Oral acute toxicity and red blood cytotoxicity of the medicinal halophyte Limoniastrum guyonianum leaf extract," Farmácia, vol. 68, pp. 1136-1146, 2020.

[54] L. Pasayeva, E. Demirpolat, H. Fatullayev, and O. Tugay, "Cytotoxic and phytochemical investigation of Cousinia ermenekensis Hub.-MOR,” Farmácia, vol. 68, pp. 521-525, 2020.

[55] S. S. Das, S. Alkahtani, P. Bharadwaj et al., "Molecular insights and novel approaches for targeting tumor metastasis," International Journal of Pharmaceutics, vol. 585, article 119556, 2020.

[56] D. Jain, P. Chaudhary, N. Varshney et al., "Tobacco smoking and liver cancer risk: potential avenues for carcinogenesis," Journal of Oncology, vol. 2021, 2021.

[57] J. Sharifi-Rad, C. Quispe, M. Butnariu et al., "Chitosan nanoparticles as a promising tool in nanomedicine with particular emphasis on oncological treatment," Cancer Cell International, vol. 21, pp. 318-318, 2021.

[58] B. K. Panigrahi and A. K. Nayak, "Carbon nanotubes: an emerging drug delivery carrier in cancer therapeutics," Current Drug Delivery, vol. 17, pp. 558-576, 2020.

[59] J. Sharifi-Rad, C. Quispe, J. K. Patra et al., "Paclitaxel: application in modern oncology and nanomedicine-based cancer therapy," Oxidative Medicine and Cellular Longevity, vol. 2021, Article ID 3687700, 24 pages, 2021.

[60] S. Samarghandian, A. Borji, S. K. Farahmand, R. Afshari, and S. Davoodi, "Crocus sativus L. (saffron) stigma aqueous extract induces apoptosis in alveolar human lung cancer cells through caspase-dependent pathways activation," BioMed Research International, vol. 2013, Article ID 417928, 12 pages, 2013.

[61] F. Vali, V. Changizi, and M. Safa, "Synergistic apoptotic effect of crocin and paclitaxel or crocin and radiation on MCF-7 cells, a type of breast cancer cell line," International Journal of Breast Cancer, vol. 2015, Article ID 139349, 7 pages, 2015.

[62] M. Mousavi, J. Baharara, and M. Asadi-Samani, "Anti-angiogenesis effect of Crocous sativus L. extract on matrix metalloproteinase gene activities in human breast carcinoma cells," Journal of HerbMed Pharmacology, vol. 3, pp. 101-105, 2014.

[63] J. Escribano, G. L. Alonso, M. Coca-Prados, and J. A. Fernandez, "Crocin, safranal and picrocrocin from saffron (Crocus sativus L.) inhibit the growth of human cancer cells in vitro," Cancer Letters, vol. 100, pp. 23-30, 1996.

[64] Y. Sun, H. J. Xu, Y. X. Zhao et al., "Crocin exhibits antitumor effects on human leukemia HL-60 cells in vitro and in vivo," Evidence-based Complementary and Alternative Medicine: Ecam, vol. 2013, article 690164, 7 pages, 2013.

[65] C. I. Tuberoso, A. Rosa, P. Montoro, M. A. Fenu, and C. Pizza, "Antioxidant activity, cytotoxic activity and metabolic profiling of juices obtained from saffron (Crocus sativus L.) floral by-products," Food Chemistry, vol. 199, pp. 18-27, 2016.

[66] O. Zlatian, A. T. Balasoiu, M. Balasoiu et al., "Antimicrobial resistance in bacterial pathogens among hospitalised patients with severe invasive infections," Experimental and Therapeutic Medicine, vol. 16, pp. 4499-4510, 2018.
[67] A. Ungureanu, O. Zlatian, G. Mitroi et al., "Staphylococcus aureus colonisation in patients from a primary regional hospital," Molecular Medicine Reports, vol. 16, pp. 8771-8780, 2017.

[68] Y. Taheri, N. Joković, J. Vitorović, O. Grundmann, A. Maroyi, and D. Calina, "The burden of the serious and difficult-to-treat infections and a new antibiotic available: cefiderocol," Frontiers in Pharmacology, vol. 11, 2021.

[69] S. Muzaffar, S. A. Rather, and K. Z. Khan, "In vitro bactericidal and fungicidal activities of various extracts of saffron (Crocus sativus L.) stigmas from Jammu \& Kashmir, India," Cogent Food \& Agriculture, vol. 2, p. 1158999, 2016.

[70] E. Kakouri, D. Daferera, S. Paramithiotis, K. Astraka, E. H. Drosinos, and M. G. Polissiou, "Crocus sativus L. tepals: the natural source of antioxidant and antimicrobial factors," Journal of Applied Research on Medicinal and Aromatic Plants, vol. 4, pp. 66-74, 2017.

[71] R. A. Hussein, N. A. Salih, and N. Eman Thabit, "Bioactivity of crocin pigment of saffron plant," Plant Archives, vol. 18, pp. 357-364, 2018.

[72] B. Cenci-Goga, R. Torricelli, Y. Hosseinzadeh Gonabad et al., "In vitro bactericidal activities of various extracts of saffron (Crocus sativus L.) stigmas from Torbat-e Heydarieh, Gonabad and Khorasan, Iran," Microbiology Research, vol. 9, no. 1, 2018.

[73] R. R. Mititelu, R. Padureanu, M. Bacanoiu et al., "Inflammatory and oxidative stress markers-mirror tools in rheumatoid arthritis," Biomedicine, vol. 8, p. 14, 2020.

[74] A. O. Docea, D. Calina, A. M. Buga et al., "The effect of silver nanoparticles on antioxidant/pro-oxidant balance in a murine model," International Journal of Molecular Sciences, vol. 21, p. 17, 2020.

[75] T. Docea, C. Tsarouhas, Z. Mitrut, S.-R. Kovatsi, S. Dardiotis, and D. Lazopoulos, "A mechanistic and pathophysiological approach for stroke associated with drugs of abuse," Journal of Clinical Medicine, vol. 8, 2019.

[76] R. Padureanu, C. V. Albu, R. R. Mititelu et al., "Oxidative stress and inflammation interdependence in multiple sclerosis," Journal of Clinical Medicine, vol. 8, 2019.

[77] B. Salehi, A. Rescigno, T. Dettori et al., "Avocado-soybean unsaponifiables: a panoply of potentialities to be exploited," Biomolecules, vol. 10, 2020.

[78] B. Salehi, M. S. Shetty, N. V. Anil Kumar et al., "Veronica plants-drifting from farm to traditional healing, food application, and phytopharmacology," Molecules, vol. 24, 2019.

[79] M. Sharifi-Rad, N. V. Anil Kumar, P. Zucca et al., "Lifestyle, oxidative stress, and antioxidants: back and forth in the pathophysiology of chronic diseases," Frontiers in Physiology, vol. 11, 2020.

[80] C. D. Kanakis, P. A. Tarantilis, H. A. Tajmir-Riahi, and M. G. Polissiou, "Crocetin, dimethylcrocetin, and safranal bind human serum albumin: stability and antioxidative properties," Journal of Agricultural and Food Chemistry, vol. 55, pp. 970-977, 2007.

[81] G. Zengin, M. Z. Aumeeruddy, A. Diuzheva et al., "A comprehensive appraisal on Crocus chrysanthus (Herb.) Herb. flower extracts with HPLC-MS/MS profiles, antioxidant and enzyme inhibitory properties," Journal of Pharmaceutical and Biomedical Analysis, vol. 164, pp. 581-589, 2019.

[82] Y. Chen, H. Zhang, X. Tian et al., "Antioxidant potential of crocins and ethanol extracts of Gardenia jasminoides ELLIS and Crocus sativus L.: a relationship investigation between 
antioxidant activity and crocin contents," Food Chemistry, vol. 109, pp. 484-492, 2008.

[83] E. Karimi, E. Oskoueian, R. Hendra, and H. Z. Jaafar, "Evaluation of Crocus sativus L. stigma phenolic and flavonoid compounds and its antioxidant activity," Molecules, vol. 15, no. 9, pp. 6244-6256, 2010.

[84] R. Sánchez-Vioque, M. F. Rodríguez-Conde, J. V. ReinaUreña, M. A. Escolano-Tercero, D. Herraiz-Peñalver, and O. Santana-Méridas, "In vitro antioxidant and metal chelating properties of corm, tepal and leaf from saffron (Crocus sativus L.)," Industrial Crops and Products, vol. 39, pp. 149153, 2012.

[85] T. Ochiai, S. Ohno, S. Soeda, H. Tanaka, Y. Shoyama, and H. Shimeno, "Crocin prevents the death of rat pheochromyctoma (PC-12) cells by its antioxidant effects stronger than those of alpha-tocopherol," Neuroscience Letters, vol. 362, pp. 61-64, 2004.

[86] S. I. Bukhari, B. Pattnaik, S. Rayees, S. Kaul, and M. K. Dhar, "Safranal of Crocus sativus L. inhibits inducible nitric oxide synthase and attenuates asthma in a mouse model of asthma," Phytotherapy research: PTR, vol. 29, pp. 617-627, 2015.

[87] S. W. Jessie and T. P. Krishnakantha, "Inhibition of human platelet aggregation and membrane lipid peroxidation by food spice, saffron," Molecular and Cellular Biochemistry, vol. 278, pp. 59-63, 2005.

[88] S. A. Moallem, A. T. Hariri, M. Mahmoudi, and H. Hosseinzadeh, "Effect of aqueous extract of Crocus sativus L. (saffron) stigma against subacute effect of diazinon on specific biomarkers in rats," Toxicology and Industrial Health, vol. 30, pp. 141-146, 2014.

[89] E. C. Urrutia, L. Riverón-Negrete, F. Abdullaev et al., "Saffron extract ameliorates oxidative damage and mitochondrial dysfunction in the rat brain," Acta Horticulturae, vol. 739, no. 739, pp. 359-366, 2007.

[90] F. I. Abdullaev, L. Riveron-Negrete, H. Caballero-Ortega et al., "Use of in vitro assays to assess the potential antigenotoxic and cytotoxic effects of saffron (Crocus sativus L.)," Toxicology In Vitro, vol. 17, no. 5-6, pp. 731-736, 2003.

[91] J. Sharifi-Rad, C. F. Rodrigues, F. Sharopov et al., "Diet, lifestyle and cardiovascular diseases: linking pathophysiology to cardioprotective effects of natural bioactive compounds," International Journal of Environmental Research and Public Health, vol. 17, 2020.

[92] H. Nemati, M. H. Boskabady, and H. Ahmadzadef Vostakolaei, "Stimulatory effect of Crocus sativus (saffron) on beta2adrenoceptors of guinea pig tracheal chains," Phytomedicine, vol. 15, pp. 1038-1045, 2008.

[93] M. H. Boskabady, M. Ghasemzadeh Rahbardar, H. Nemati, and M. Esmaeilzadeh, "Inhibitory effect of Crocus sativus (saffron) on histamine (H1) receptors of guinea pig tracheal chains," Die Pharmazie, vol. 65, pp. 300-305, 2010.

[94] U. H. Joshi, T. H. Ganatra, P. N. Bhalodiya, T. R. Desai, and P. R. Tirgar, "Comparative review on harmless herbs with allopathic remedies as anti-hypertensive," Research Journal of Pharmaceutical, Biological and Chemical Sciences, vol. 3, pp. 673-687, 2012.

[95] F. Yoshino, A. Yoshida, N. Umigai, K. Kubo, and M. C. Lee, "Crocetin reduces the oxidative stress induced reactive oxygen species in the stroke-prone spontaneously hypertensive rats (SHRSPs) brain," Journal of Clinical Biochemistry and Nutrition, vol. 49, pp. 182-187, 2011.
[96] A. Milajerdi, V. Bitarafan, and M. Mahmoudi, "A review on the effects of saffron extract and its constituents on factors related to neurologic," Cardiovascular and Gastrointestinal Diseases, vol. 3, pp. 9-28, 2015.

[97] B. M. Razavi and H. Hosseinzadeh, "Saffron: a promising natural medicine in the treatment of metabolic syndrome," Journal of the Science of Food and Agriculture, vol. 97, pp. 16791685, 2017.

[98] M. Imenshahidi, H. Hosseinzadeh, and Y. Javadpour, "Hypotensive effect of aqueous saffron extract (Crocus sativus L.) and its constituents, safranal and crocin, in normotensive and hypertensive rats," Phytotherapy research: PTR, vol. 24, pp. 990-994, 2010.

[99] M. Imenshahidi, B. M. Razavi, A. Faal, A. Gholampoor, S. M. Mousavi, and H. Hosseinzadeh, "The effect of chronic administration of saffron (Crocus sativus) stigma aqueous extract on systolic blood pressure in rats," Jundishapur Journal of Natural Pharmaceutical Products, vol. 8, pp. 175-179, 2013.

[100] M. Fatehi, T. Rashidabady, and Z. Fatehi-Hassanabad, "Effects of Crocus sativus petals' extract on rat blood pressure and on responses induced by electrical field stimulation in the rat isolated vas deferens and guinea-pig ileum," Journal of Ethnopharmacology, vol. 84, pp. 199-203, 2003.

[101] J. Sachdeva, V. Tanwar, M. Golechha et al., "Crocus sativus L. (saffron) attenuates isoproterenol-induced myocardial injury via preserving cardiac functions and strengthening antioxidant defense system," Experimental and Toxicologic Pathology, vol. 64, pp. 557-564, 2012.

[102] V. Khori, A. M. Alizadeh, H. Yazdi et al., "Frequency-dependent electrophysiological remodeling of the AV node by hydroalcohol extract of Crocus sativus L. (saffron) during experimental atrial fibrillation: the role of endogenous nitric oxide," Phytotherapy research: PTR, vol. 26, pp. 826-832, 2012.

[103] M. H. Boskabady, M. N. Shafei, A. Shakiba, and H. S. Sefidi, "Effect of aqueous-ethanol extract from Crocus sativus (saffron) on guinea-pig isolated heart," Phytotherapy research: PTR, vol. 22, pp. 330-334, 2008.

[104] Z. Jahanbakhsh, B. Rasoulian, M. Jafari et al., "Protective effect of crocin against reperfusion-induced cardiac arrhythmias in anaesthetized rats," EXCLI Journal, vol. 11, pp. 2029, 2012.

[105] R. Mehdizadeh, M. R. Parizadeh, A. R. Khooei, S. Mehri, and H. Hosseinzadeh, "Cardioprotective effect of saffron extract and safranal in isoproterenol-induced myocardial infarction in Wistar rats," Iranian Journal of Basic Medical Sciences, vol. 16, pp. 56-63, 2013.

[106] L. Yang, Z. Qian, Y. Yang et al., "Involvement of Ca2+ in the inhibition by crocetin of platelet activity and thrombosis formation," Journal of Agricultural and Food Chemistry, vol. 56, pp. 9429-9433, 2008.

[107] S. Joukar, H. Najafipour, M. Khaksari et al., “The effect of saffron consumption on biochemical and histopathological heart indices of rats with myocardial infarction," Cardiovascular Toxicology, vol. 10, pp. 66-71, 2010.

[108] S. N. Goyal, S. Arora, A. K. Sharma et al., "Preventive effect of crocin of Crocus sativus on hemodynamic, biochemical, histopathological and ultrastuctural alterations in isoproterenol-induced cardiotoxicity in rats," Phytomedicine, vol. 17, pp. 227-232, 2010.

[109] G. Xu, Z. Gong, W. Yu, L. Gao, S. He, and Z. Qian, "Increased expression ratio of $\mathrm{Bcl}-2 / \mathrm{Bax}$ is associated with crocin- 
mediated apoptosis in bovine aortic endothelial cells," Basic \& Clinical Pharmacology \& Toxicology, vol. 100, pp. 31-35, 2007.

[110] S. Y. He, Z. Y. Qian, N. Wen, F. T. Tang, G. L. Xu, and C. H. Zhou, "Influence of crocetin on experimental atherosclerosis in hyperlipidamic-diet quails," European Journal of Pharmacology, vol. 554, pp. 191-195, 2007.

[111] S. Zheng, Z. Qian, F. Tang, and L. Sheng, "Suppression of vascular cell adhesion molecule- 1 expression by crocetin contributes to attenuation of atherosclerosis in hypercholesterolemic rabbits," Biochemical Pharmacology, vol. 70, pp. 1192-1199, 2005.

[112] M. Kamalipour and S. Akhondzadeh, "Cardiovascular effects of saffron: an evidence-based review," The Journal of Tehran Heart Center, vol. 6, no. 2, pp. 59-61, 2011.

[113] M. Hemmati, E. Zohoori, O. Mehrpour et al., "Anti-atherogenic potential of jujube, saffron and barberry: anti-diabetic and antioxidant actions," EXCLI Journal, vol. 14, pp. 908915, 2015.

[114] S. Chermahini, F. Abd Majid, M. Sarmidi, E. Taghizadeh, and S. Salehnezhad, "Impact of saffron as an anti-cancer and antitumor herb," African Journal of Pharmacy and Pharmacology, vol. 4, pp. 834-840, 2010.

[115] F. I. Abdullaev, "Antitumor effect of saffron (Crocus sativus L.): overview and perspectives," Acta Horticulturae, no. 650, pp. 491-499, 2004.

[116] H. Mollaei, R. Safaralizadeh, E. Babaei, M. R. Abedini, and R. Hoshyar, "The anti-proliferative and apoptotic effects of crocin on chemosensitive and chemoresistant cervical cancer cells," Biomedicine \& pharmacotherapy = Biomedecine \& pharmacotherapie, vol. 94, pp. 307-316, 2017.

[117] E. S. el Daly, "Protective effect of cysteine and vitamin E, Crocus sativus and Nigella sativa extracts on cisplatin-induced toxicity in rats," Journal de Pharmacie de Belgique, vol. 53, no. 2, 1998.

[118] A. Amin, A. A. Hamza, K. Bajbouj, S. S. Ashraf, and S. Daoud, "Saffron: a potential candidate for a novel anticancer drug against hepatocellular carcinoma," Hepatology, vol. 54, pp. 857-867, 2011.

[119] K. Premkumar, S. K. Abraham, S. T. Santhiya, and A. Ramesh, "Inhibitory effects of aqueous crude extract of Saffron (Crocus sativus L.) on chemical-induced genotoxicity in mice," Asia Pacific Journal of Clinical Nutrition, vol. 12, no. 4, pp. 474-476, 2003.

[120] S. A. Ordoudi, C. D. Befani, N. Nenadis, G. G. Koliakos, and M. Z. Tsimidou, "Further examination of antiradical properties of Crocus sativus stigmas extract rich in crocins," Journal of Agricultural and Food Chemistry, vol. 57, pp. 3080-3086, 2009.

[121] H. Hosseinzadeh and V. Khosravan, "Anticonvulsant effects of aqueous and ethanolic extracts of Crocus sativus L. stigmas in mice," Archives of Iranian Medicine, vol. 5, pp. 44-50, 2002.

[122] M. Sugiura, Y. Shoyama, H. Saito, and K. Abe, "Crocin (crocetin di-gentiobiose ester) prevents the inhibitory effect of ethanol on long-term potentiation in the dentate gyrus in vivo," The Journal of Pharmacology and Experimental Therapeutics, vol. 271, pp. 703-707, 1994.

[123] A. Ghazavi, G. Mosayebi, H. Salehi, and H. Abtahi, "Effect of ethanol extract of saffron (Crocus sativus L.) on the inhibition of experimental autoimmune encephalomyelitis in C57bl/6 mice," Pakistan Journal of Biological Sciences: PJBS, vol. 12, no. 9, pp. 690-695, 2009.
[124] H. R. Sadeghnia, M. A. Cortez, D. Liu, H. Hosseinzadeh, and O. C. Snead 3rd., "Antiabsence effects of safranal in acute experimental seizure models: EEG and autoradiography," Journal of Pharmacy \& Pharmaceutical Sciences, vol. 11, pp. 1-14, 2008.

[125] S. M. Naghibi, M. Hosseini, F. Khani et al., "Effect of aqueous extract of Crocus sativus L. on morphine-induced memory impairment," Advances in Pharmacological Sciences, vol. 2012, Article ID 494367, 7 pages, 2012.

[126] S. Zheng, Z. Qian, N. Wen, and L. Xi, "Crocetin suppresses angiotensin II-induced vascular smooth-muscle cell proliferation through inhibition of ERK1/2 activation and cell-cycle progression," Journal of Cardiovascular Pharmacology, vol. 50, pp. 519-525, 2007.

[127] M. R. Khazdair, M. H. Boskabady, M. Hosseini, R. Rezaee, and A. M. Tsatsakis, "The effects of Crocus sativus (saffron) and its constituents on nervous system: a review," Avicenna Journal of Phytomedicine, vol. 5, pp. 376-391, 2015.

[128] B. P. V. Sunanda, B. Rammohan, K. Amitabh, and B. L. Kudagi, "The effective study of aqueous extract of Crocus sativus Linn. In chemical induced convulsants in rats," World Journal of Pharmacy \& Pharmaceutical Sciences, vol. 3, pp. 1175-1182, 2014.

[129] D. Calina, A. M. Buga, M. Mitroi et al., "The treatment of cognitive, behavioural and motor impairments from brain injury and neurodegenerative diseases through cannabinoid system modulation-evidence from in vivo studies," Journal of Clinical Medicine, vol. 9, 2020.

[130] D. Tsoukalas, A. Buga, A. Docea et al., "Reversal of brain aging by targeting telomerase: a nutraceutical approach," International Journal of Molecular Medicine, vol. 48, 2021.

[131] B. Salehi, D. Calina, A. Docea et al., "Curcumin's nanomedicine formulations for therapeutic application in neurological diseases," Journal of Clinical Medicine, vol. 9, 2020.

[132] S. H. Alavizadeh and H. Hosseinzadeh, "Bioactivity assessment and toxicity of crocin: a comprehensive review," Food and Chemical Toxicology, vol. 64, pp. 65-80, 2014.

[133] M. B. Ebrahim-Habibi, M. Amininasab, A. Ebrahim-Habibi, M. Sabbaghian, and M. Nemat-Gorgani, "Fibrillation of alpha-lactalbumin: effect of crocin and safranal, two natural small molecules from Crocus sativus," Biopolymers, vol. 93, pp. 854-865, 2010.

[134] R. K. Singla and V. G. C. Bhat, "An overview. Indo Global Journal of Pharmaceutical Sciences," Indo Global Journal of Pharmaceutical Sciences, vol. 1, pp. 281-286, 2011.

[135] M. A. Papandreou, C. D. Kanakis, M. G. Polissiou et al., "Inhibitory activity on amyloid-beta aggregation and antioxidant properties of Crocus sativus stigmas extract and its crocin constituents," Journal of Agricultural and Food Chemistry, vol. 54, pp. 8762-8768, 2006.

[136] M. Khalili, Z. Kiasalari, B. Rahmati, and J. Narenjkar, "Behavioral and histological analysis of Crocus sativus effect in intracerebroventricular streptozotocin model of Alzheimer disease in rats," Iranian Journal of Pathology, vol. 5, pp. 2733, 2010.

[137] M. Khalili and F. Hamzeh, "Effects of active constituents of Crocus sativus L., crocin on streptozocin-induced model of sporadic Alzheimer's disease in male rats," Iranian Biomedical Journal, vol. 14, pp. 59-65, 2010.

[138] B. Ghadrdoost, A. A. Vafaei, A. Rashidy-Pour et al., "Protective effects of saffron extract and its active constituent crocin 
against oxidative stress and spatial learning and memory deficits induced by chronic stress in rats," European Journal of Pharmacology, vol. 667, pp. 222-229, 2011.

[139] G. D. Geromichalos, F. N. Lamari, M. A. Papandreou et al., "Saffron as a source of novel acetylcholinesterase inhibitors: molecular docking and in vitro enzymatic studies," Journal of Agricultural and Food Chemistry, vol. 60, pp. 6131-6138, 2012.

[140] M. Sharifi-Rad, C. Lankatillake, D. A. Dias et al., "Impact of natural compounds on neurodegenerative disorders: from preclinical to pharmacotherapeutics," Journal of Clinical Medicine, vol. 9, no. 4, p. 19, 2020.

[141] L. Tamegart, A. Abbaoui, R. Makbal et al., "Crocus sativus restores dopaminergic and noradrenergic damages induced by lead in Meriones shawi: a possible link with Parkinson's disease," Acta Histochemica, vol. 121, pp. 171-181, 2019.

[142] D. Tsoukalas, O. Zlatian, M. Mitroi et al., "A novel nutraceutical formulation can improve motor activity and decrease the stress level in a murine model of middle-age animals," Journal of Clinical Medicine, vol. 10, no. 4, p. 624, 2021.

[143] A. M. Aloizou, V. Siokas, G. Pateraki et al., “Thinking outside the ischemia box: advancements in the use of multiple sclerosis drugs in ischemic stroke," Journal of Clinical Medicine, vol. 10, no. 4, p. 19, 2021.

[144] J. Sharifi-Rad, C. Quispe, J. Herrera-Bravo et al., "A pharmacological perspective on plant-derived bioactive molecules for epilepsy," Neurochemical Research, vol. 46, no. 9, pp. 22052225, 2021.

[145] A. S. Ahmad, M. A. Ansari, M. Ahmad et al., "Neuroprotection by crocetin in a hemi-parkinsonian rat model," Pharmacology, Biochemistry, and Behavior, vol. 81, pp. 805-813, 2005.

[146] S. Purushothuman, C. Nandasena, C. L. Peoples et al., "Saffron pre-treatment offers neuroprotection to Nigral and retinal dopaminergic cells of MPTP-treated mice," Journal of Parkinson's Disease, vol. 3, pp. 77-83, 2013.

[147] Y. Wang, T. Han, Y. Zhu et al., "Antidepressant properties of bioactive fractions from the extract of Crocus sativus L," Journal of Natural Medicines, vol. 64, pp. 24-30, 2010.

[148] G. R. Karimi, H. Hosseinzadeh, and P. P. Khalegh, "Study of antidepressant effect of aqueous and ethanolic extract of Crocus sativus in mice," Iranian Journal of Basic Medical Sciences, vol. 4, pp. 11-15, 2001.

[149] H. Hosseinzadeh, V. Motamedshariaty, and F. Hadizadeh, "Antidepressant effect of kaempferol, a constituent of saffron (Crocus sativus) petal, in mice and rats," Pharmacology, vol. 2, pp. 367-370, 2007.

[150] J. F. Cryan and I. Lucki, "Antidepressant-like behavioral effects mediated by 5-Hydroxytryptamine(2C) receptors," The Journal of Pharmacology and Experimental Therapeutics, vol. 295, pp. 1120-1126, 2000.

[151] B. Salehi, J. Sharifi-Rad, F. Cappellini et al.et al., "The therapeutic potential of anthocyanins: current approaches based on their molecular mechanism of action," Frontiers in Pharmacology, vol. 11, p. 20, 2020.

[152] H. Hosseinzadeh and H. R. Sadeghnia, "Safranal, a constituent of Crocus sativus (saffron), attenuated cerebral ischemia induced oxidative damage in rat hippocampus," Journal of Pharmacy \& Pharmaceutical Sciences, vol. 8, no. 3, pp. 394399, 2005.
[153] H. R. Sadeghnia, M. Kamkar, E. Assadpour, M. T. Boroushaki, and A. Ghorbani, "Protective effect of safranal, a constituent of Crocus sativus, on Quinolinic acid-induced oxidative damage in rat hippocampus," Iranian Journal of Basic Medical Sciences, vol. 16, pp. 73-82, 2013.

[154] H. Hosseinzadeh, H. R. Sadeghnia, and A. Rahimi, "Effect of safranal on extracellular hippocampal levels of glutamate and aspartate during kainic acid treatment in anesthetized rats," Planta Medica, vol. 74, pp. 1441-1445, 2008.

[155] X. Bie, Y. Chen, X. Zheng, and H. Dai, “The role of crocetin in protection following cerebral contusion and in the enhancement of angiogenesis in rats," Fitoterapia, vol. 82, pp. 9971002, 2011.

[156] H. Sahraeil, Z. Fatahi, A. H. Rohani, A. Eidi, Z. Hooshmandi, and S. A. Tavallaei, "Ethanolic extract of saffron and its constituent crocin diminish stress-induced metabolic signs and alterations of dopamine-related behaviours in rats," International Research Journal of Pharmacy and Pharmacology, vol. 2, pp. 165-173, 2012.

[157] H. Hosseinzadeh, H. R. Sadeghnia, F. A. Ghaeni, V. S. Motamedshariaty, and S. A. Mohajeri, "Effects of saffron (Crocus sativus L.) and its active constituent, crocin, on recognition and spatial memory after chronic cerebral hypoperfusion in rats," Phytotherapy research: PTR, vol. 26, pp. 381-386, 2012.

[158] A. Vakili, M. R. Einali, and A. R. Bandegi, "Protective effect of crocin against cerebral ischemia in a dose-dependent manner in a rat model of ischemic stroke," Journal of Stroke and Cerebrovascular Diseases: The Official Journal of National Stroke Association, vol. 23, pp. 106-113, 2014.

[159] Y. Q. Zheng, J. X. Liu, J. N. Wang, and L. Xu, "Effects of crocin on reperfusion-induced oxidative/nitrative injury to cerebral microvessels after global cerebral ischemia," Brain Research, vol. 1138, pp. 86-94, 2007.

[160] K. N. Nam, Y. M. Park, H. J. Jung et al., "Anti-inflammatory effects of crocin and crocetin in rat brain microglial cells," European Journal of Pharmacology, vol. 648, pp. 110-116, 2010.

[161] K. Abe and H. Saito, "Effects of saffron extract and its constituent crocin on learning behaviour and long-term potentiation," Phytotherapy research: PTR, vol. 14, pp. 149-152, 2000.

[162] N. Pitsikas and N. Sakellaridis, "Crocus sativus L. Extracts antagonize memory impairments in different behavioural tasks in the rat," Behavioural Brain Research, vol. 173, pp. 112-115, 2006.

[163] M. R. Ghadami and A. Pourmotabbed, "The effect of crocin on scopolamine induced spatial learning and memory deficits in rats," Physiol-Pharmacol, vol. 12, pp. 287-295, 2009.

[164] S. Saleem, M. Ahmad, A. S. Ahmad et al., "Effect of saffron (Crocus sativus) on neurobehavioral and neurochemical changes in cerebral ischemia in rats," Journal of Medicinal Food, vol. 9, pp. 246-253, 2006.

[165] K. M. Debatin, D. Poncet, and G. Kroemer, "Chemotherapy: targeting the mitochondrial cell death pathway," Oncogene, vol. 21, pp. 8786-8803, 2002.

[166] H. Hosseinzadeh, H. R. Sadeghnia, T. Ziaee, and A. Danaee, "Protective effect of aqueous saffron extract (Crocus sativus L.) and crocin, its active constituent, on renal ischemia/reperfusion-induced oxidative damage in rats," Journal of Pharmacy \& Pharmaceutical Sciences, vol. 8, no. 3, pp. 387-393, 2005. 
[167] Z. I. Linardaki, M. G. Orkoula, A. G. Kokkosis, F. N. Lamari, and M. Margarity, "Investigation of the neuroprotective action of saffron (Crocus sativus L.) in aluminum-exposed adult mice through behavioral and neurobiochemical assessment," Food and Chemical Toxicology, vol. 52, pp. 163-170, 2013.

[168] M. Lechtenberg, D. Schepmann, M. Niehues, N. Hellenbrand, B. Wunsch, and A. Hensel, "Quality and functionality of saffron: quality control, species assortment and affinity of extract and isolated saffron compounds to NMDA and sigmal (sigma-1) receptors," Planta Medica, vol. 74, pp. 764-772, 2008.

[169] S. Nasri, S. Y. Hosseini, H. Sahraei, and H. Zardooz, "Inhibition of pain and inflamation induced by formalin in male mice by ethanolic extract of saffron (Crocus sativus) and its constituents crocin and safranal," Trauma Monthly, vol. 15, pp. 189-195, 2010.

[170] B. Amin and H. Hosseinzadeh, "Evaluation of aqueous and ethanolic extracts of saffron, Crocus sativus L., and its constituents, safranal and crocin in allodynia and hyperalgesia induced by chronic constriction injury model of neuropathic pain in rats," Fitoterapia, vol. 83, pp. 888-895, 2012.

[171] H. Hosseinzadeh and Z. Jahanian, "Effect of Crocus sativus L. (saffron) stigma and its constituents, crocin and safranal, on morphine withdrawal syndrome in mice," Phytotherapy research: PTR, vol. 24, pp. 726-730, 2010.

[172] H. Haghighizad, A. Pourmotabbed, H. Sahraei, M. R. Ghadami, S. Ghadami, and M. Kamalinejad, "Protective effect of saffron extract on morphine-induced inhibition of spatial learning and memory in rat," Physiol-Pharmacol, vol. 12, pp. 170-179, 2008.

[173] K. Premkumar, C. Thirunavukkarasu, S. K. Abraham, S. T. Santhiya, and A. Ramesh, "Protective effect of saffron (Crocus sativus L.) aqueous extract against genetic damage induced by anti-tumor agents in mice," Human \& Experimental Toxicology, vol. 25, pp. 79-84, 2006.

[174] S. M. Asdaq and M. N. Inamdar, "Potential of Crocus sativus (saffron) and its constituent, crocin, as hypolipidemic and antioxidant in rats," Applied Biochemistry and Biotechnology, vol. 162, pp. 358-372, 2010.

[175] L. Sheng, Z. Qian, S. Zheng, and L. Xi, "Mechanism of hypolipidemic effect of crocin in rats: crocin inhibits pancreatic lipase," European Journal of Pharmacology, vol. 543, pp. 116-122, 2006.

[176] S. Y. He, Z. Y. Qian, F. T. Tang, N. Wen, G. L. Xu, and L. Sheng, "Effect of crocin on experimental atherosclerosis in quails and its mechanisms," Life Sciences, vol. 77, pp. 907-921, 2005.

[177] J. C. Cousins and T. L. Miller, "The effects of crocetin on plasma lipids in rats," The Ohio Journal of Science, vol. 85, pp. 97-101, 1985.

[178] S. Padhi, A. K. Nayak, and A. Behera, "Type II diabetes mellitus: a review on recent drug based therapeutics," Biomedicine \& Pharmacotherapy, vol. 131, p. 110708, 2020.

[179] R. Nasimi Doost Azgomi, A. Karimi, M. M. Zarshenas, and A. Moini Jazani, "The mechanisms of saffron (Crocus sativus) on the inflammatory pathways of diabetes mellitus: a systematic review," Diabetes and Metabolic Syndrome: Clinical Research and Reviews, vol. 16, p. 102365, 2021.

[180] S. Samarghandian, M. Azimi-Nezhad, and T. Farkhondeh, "Immunomodulatory and antioxidant effects of saffron aqueous extract (Crocus sativus L.) on streptozotocin-induced dia- betes in rats," Indian Heart Journal, vol. 69, pp. 151-159, 2017.

[181] S. Kianbakht and R. Hajiaghaee, "Anti-hyperglycemic effects of saffron and its active constituents, crocin and safranal, in alloxan-induced diabetic rats," Journal of Medicinal Plants, vol. 3, pp. 82-89, 2011.

[182] D. Mohajeri, G. Mousavi, and Y. Doustar, “Antihyperglycemic and pancreas-protective effects of Crocus sativus L. (saffron) stigma ethanolic extract on rats with alloxan-induced diabetes," Journal of Biological Sciences, vol. 9, pp. 302-310, 2009.

[183] A. Arasteh, A. Aliyev, S. Khamnei, A. Delazar, M. Mesgari, and Y. Mehmannavaz, "Effects of hydromethanolic extract of saffron (Crocus sativus) on serum glucose, insulin and cholesterol levels in healthy male rats," Journal of Medicinal Plant Research, vol. 4, pp. 397-402, 2010.

[184] L. Xi, Z. Qian, X. Shen, N. Wen, and Y. Zhang, "Crocetin prevents dexamethasone-induced insulin resistance in rats," Planta Medica, vol. 71, pp. 917-922, 2005.

[185] L. Xi, Z. Qian, G. Xu, C. Zhou, and S. Sun, "Crocetin attenuates palmitate-induced insulin insensitivity and disordered tumor necrosis factor-alpha and adiponectin expression in rat adipocytes," British Journal of Pharmacology, vol. 151, pp. 610-617, 2007.

[186] M. Xiang, Z. Y. Qian, C. H. Zhou, J. Liu, and W. N. Li, “Crocetin inhibits leukocyte adherence to vascular endothelial cells induced by AGEs," Journal of Ethnopharmacology, vol. 107, pp. 25-31, 2006.

[187] M. Xiang, M. Yang, C. Zhou, J. Liu, W. Li, and Z. Qian, "Crocetin prevents AGEs-induced vascular endothelial cell apoptosis," Pharmacological Research, vol. 54, pp. 268274, 2006.

[188] M. H. Boskabady, A. Tabatabaee, and G. Byrami, "The effect of the extract of Crocus sativus and its constituent safranal, on lung pathology and lung inflammation of ovalbumin sensitized guinea-pigs," Phytomedicine, vol. 19, pp. 904-911, 2012.

[189] H. Hosseinzadeh and J. Ghenaati, "Evaluation of the antitussive effect of stigma and petals of saffron (Crocus sativus) and its components, safranal and crocin in guinea pigs," Fitoterapia, vol. 77, pp. 446-448, 2006.

[190] M. H. Boskabady, M. G. Rahbardar, and Z. Jafari, "The effect of safranal on histamine $(\mathrm{H}(1))$ receptors of guinea pig tracheal chains," Fitoterapia, vol. 82, pp. 162-167, 2011.

[191] P. Shukurova and R. Babaev, "A study into the effectiveness of the application of saffron extract in ocular pathologies in experiment," Georgian Medical News, pp. 38-42, 2010.

[192] R. Maccarone, S. Di Marco, and S. Bisti, "Saffron supplement maintains morphology and function after exposure to damaging light in mammalian retina," Investigative Ophthalmology \& Visual Science, vol. 49, pp. 1254-1261, 2008.

[193] S. Predieri, M. Magli, E. Gatti, F. Camilli, P. Vignolini, and A. Romani, "Chemical composition and sensory evaluation of saffron," Food, vol. 10, 2021.

[194] B. Xuan, Y. H. Zhou, N. Li, Z. D. Min, and G. C. Chiou, "Effects of crocin analogs on ocular blood flow and retinal function," Journal of Ocular Pharmacology and Therapeutics, vol. 15, pp. 143-152, 1999.

[195] Y. Ohno, T. Nakanishi, N. Umigai, K. Tsuruma, M. Shimazawa, and H. Hara, "Oral administration of crocetin prevents inner retinal damage induced by N-methyl-Daspartate in mice," European Journal of Pharmacology, vol. 690, pp. 84-89, 2012. 
[196] F. Berger, A. Hensel, and K. Nieber, "Saffron extract and trans-crocetin inhibit glutamatergic synaptic transmission in rat cortical brain slices," Neuroscience, vol. 180, pp. 238247, 2011.

[197] Y. Qi, L. Chen, L. Zhang, W. B. Liu, X. Y. Chen, and X. G. Yang, "Crocin prevents retinal ischaemia/reperfusion injury-induced apoptosis in retinal ganglion cells through the PI3K/AKT signalling pathway," Experimental Eye Research, vol. 107, pp. 44-51, 2013.

[198] S. Soeda, T. Ochiai, L. Paopong, H. Tanaka, Y. Shoyama, and H. Shimeno, "Crocin suppresses tumor necrosis factor-alphainduced cell death of neuronally differentiated PC-12 cells," Life Sciences, vol. 69, pp. 2887-2898, 2001.

[199] M. Yamauchi, K. Tsuruma, S. Imai et al., "Crocetin prevents retinal degeneration induced by oxidative and endoplasmic reticulum stresses via inhibition of caspase activity," European Journal of Pharmacology, vol. 650, pp. 110-119, 2011.

[200] H. Hosseinzadeh and H. M. Younesi, “Antinociceptive and anti-inflammatory effects of Crocus sativus L. stigma and petal extracts in mice," BMC Pharmacology, vol. 2, pp. 7-7, 2002.

[201] H. Hosseinzadeh, M. H. Modaghegh, and Z. Saffari, "Crocus sativus L. (Saffron) extract and its active constituents (crocin and safranal) on ischemia-reperfusion in rat skeletal muscle," Evidence-based Complementary and Alternative Medicine: Ecam, vol. 6, pp. 343-350, 2009.

[202] G. Khorasani, S. J. Hosseinimehr, P. Zamani, M. Ghasemi, and A. Ahmadi, "The effect of saffron (Crocus sativus) extract for healing of second-degree burn wounds in rats," The Keio Journal of Medicine, vol. 57, no. 4, pp. 190-195, 2008.

[203] V. Magesh, J. P. Singh, K. Selvendiran, G. Ekambaram, and D. Sakthisekaran, "Antitumour activity of crocetin in accordance to tumor incidence, antioxidant status, drug metabolizing enzymes and histopathological studies," Molecular and Cellular Biochemistry, vol. 287, pp. 127-135, 2006.

[204] V. Magesh, K. DurgaBhavani, P. Senthilnathan, P. Rajendran, and D. Sakthisekaran, "In vivo protective effect of crocetin on benzo(a)pyrene-induced lung cancer in Swiss albino mice," Phytotherapy research: PTR, vol. 23, pp. 533-539, 2009.

[205] D. D. Liu, Y. L. Ye, J. Zhang, J. N. Xu, X. D. Qian, and Q. Zhang, "Distinct pro-apoptotic properties of Zhejiang saffron against human lung cancer via a caspase-8-9-3 cascade," Asian Pacific Journal of Cancer Prevention : APJCP, vol. 15, pp. 6075-6080, 2014.

[206] I. Das, R. N. Chakrabarty, and S. Das, "Saffron can prevent chemically induced skin carcinogenesis in Swiss albino mice," Asian Pacific Journal of Cancer Prevention : APJCP, vol. 5, pp. 70-76, 2004.

[207] I. Das, S. Das, and T. Saha, "Saffron suppresses oxidative stress in DMBA-induced skin carcinoma: a histopathological study," Acta Histochemica, vol. 112, pp. 317-327, 2010.

[208] A. A. Shati, F. G. Elsaid, and E. E. Hafez, "Biochemical and molecular aspects of aluminium chloride-induced neurotoxicity in mice and the protective role of Crocus sativus L. extraction and honey syrup," Neuroscience, vol. 175, pp. 6674, 2011.

[209] H. Ettehadi, N. M. Seyedeh, R. Mina et al., "Aqueous extract of saffron (Crocus sativus) increases brain dopamine and glutamate concentrations in rats," Journal of Behavioral and Brain Science, vol. 3, no. 3, pp. 315-319, 2013.
[210] H. Ghoshooni, M. Daryaafzoon, S. Sadeghi-Gharjehdagi et al., "Saffron (Crocus sativus) ethanolic extract and its constituent, safranal, inhibits morphine-induced place preference in mice," Pakistan Journal of Biological Sciences: PJBS, vol. 14, no. 20, pp. 939-944, 2011.

[211] F. Vahdati Hassani, M. Hashemzaei, E. Akbari, M. Imenshahidi, and H. Hosseinzadeh, "Effects of berberine on acquisition and reinstatement of morphine-induced conditioned place preference in mice," Avicenna Journal of Phytomedicine, vol. 6, pp. 198-204, 2016.

[212] A. Eidi, M. Kamalinejad, A. Khoshbaten et al., "Study of the effects of intra-nucleus accumbens shell injections of alcohlic extract of Crocus sativus on the acquisition and expression of morphine-induced conditioned place preference in rats," Physiol-Pharmacol, vol. 12, pp. 121-128, 2008.

[213] M. A. Papandreou, M. Tsachaki, S. Efthimiopoulos, P. Cordopatis, F. N. Lamari, and M. Margarity, "Memory enhancing effects of saffron in aged mice are correlated with antioxidant protection," Behavioural Brain Research, vol. 219, pp. 197-204, 2011.

[214] E. Tamaddonfard, A. A. Farshid, K. Eghdami, F. Samadi, and A. Erfanparast, "Comparison of the effects of crocin, safranal and diclofenac on local inflammation and inflammatory pain responses induced by carrageenan in rats," Pharmacological Reports, vol. 65, pp. 1272-1280, 2013.

[215] A. A. Noorbala, S. Akhondzadeh, N. Tahmacebi-Pour, and A. H. Jamshidi, "Hydro-alcoholic extract of Crocus sativus L. versus fluoxetine in the treatment of mild to moderate depression: a double-blind, randomized pilot trial," Journal of Ethnopharmacology, vol. 97, pp. 281-284, 2005.

[216] N. Shahmansouri, M. Farokhnia, S. H. Abbasi et al., "A randomized, double-blind, clinical trial comparing the efficacy and safety of Crocus sativus L. with fluoxetine for improving mild to moderate depression in post percutaneous coronary intervention patients," Journal of Affective Disorders, vol. 155, pp. 216-222, 2014.

[217] A. Akhondzadeh Basti, E. Moshiri, A. A. Noorbala, A. H. Jamshidi, S. H. Abbasi, and S. Akhondzadeh, "Comparison of petal of Crocus sativus L. and fluoxetine in the treatment of depressed outpatients: a pilot double-blind randomized trial," Progress in Neuro-Psychopharmacology \& Biological Psychiatry, vol. 31, pp. 439-442, 2007.

[218] A. L. Lopresti, P. D. Drummond, A. M. Inarejos-Garcia, and M. Prodanov, "Affron ${ }^{\circledR}$, a standardised extract from saffron (Crocus sativus L.) for the treatment of youth anxiety and depressive symptoms: a randomised, double-blind, placebocontrolled study," Journal of Affective Disorders, vol. 232, pp. 349-357, 2018.

[219] S. Akhondzadeh, M. S. Sabet, M. H. Harirchian et al., "Saffron in the treatment of patients with mild to moderate Alzheimer's disease: a 16-week, randomized and placebocontrolled trial," Journal of Clinical Pharmacy and Therapeutics, vol. 35, no. 5, pp. 581-588, 2010.

[220] S. Akhondzadeh, M. Shafiee Sabet, M. H. Harirchian et al., "A 22-week, multicenter, randomized, double-blind controlled trial of Crocus sativus in the treatment of mild-to-moderate Alzheimer's disease," Psychopharmacology, vol. 207, pp. 637-643, 2010.

[221] B. Mousavi, S. Z. Bathaie, F. Fadai et al., "Safety evaluation of saffron stigma (Crocus sativus L.) aqueous extract and crocin in patients with schizophrenia," Avicenna Journal of Phytomedicine, vol. 5, pp. 413-419, 2015. 
[222] S. Akhondzadeh, N. Tahmacebi-Pour, A. A. Noorbala et al., "Crocus sativus L. in the treatment of mild to moderate depression: a double-blind, randomized and placebocontrolled trial," Phytotherapy research: PTR, vol. 19, pp. 148-151, 2005.

[223] S. Moosavi, M. Ahmadi, M. Amini, B. Vazirzadeh, and I. Sari, "The effects of 40 and $80 \mathrm{mg}$ hydro-alcoholic extract of Crocus sativus in the treatment of mild to moderate depression," Journal of Mazandaran University of Medical Sciences, vol. 24, 2014.

[224] B. Salehi, A. Prakash Mishra, M. Nigam et al., "Ficus plants: state of the art from a phytochemical, pharmacological, and toxicological perspective," Phytotherapy research: PTR, vol. 35, no. 3, pp. 1187-1217, 2021.

[225] H. Hosseinzadeh, S. Sadeghi Shakib, A. Khadem Sameni, and E. Taghiabadi, "Acute and subacute toxicity of safranal, a constituent of saffron, in mice and rats," Iranian Journal of Pharmaceutical Research : IJPR, vol. 12, pp. 93-99, 2013.

[226] D. Mohajeri, M. Abbasi, A. Delazar, Y. Doustar, G. Mousavi, and B. Amouoghli Tabrizi, "Histopathological study of subacute toxicity of Crocus sativus L. (saffron) stigma total extract on liver and kidney tissues in the rat," Pharmaceutical Sciences, vol. 15, pp. 115-124, 2009.

[227] D. Mohajeri, G. Mousavi, and M. Mesgari, "Subacute toxicity of Crocus sativus L. saffron stigma ethanolic extract in rats," American Journal of Pharmacology and Toxicology, vol. 2, pp. 189-193, 2007.

[228] T. Ziaee, B. M. Razavi, and H. Hosseinzadeh, "Saffron reduced toxic effects of its constituent, safranal, in acute and subacute toxicities in rats," Jundishapur Journal of Natural Pharmaceutical Products, vol. 9, pp. 3-8, 2014.

[229] G. Karimi, N. Taiebi, H. Hosseinzadeh, and F. Shirzad, "Evaluation of subacute toxicity of aqueous extract of Crocus sativus L," Stigma and Petal in Rats, vol. 4, pp. 29-35, 2004.

[230] M. Khayatnouri, S. Safavi, S. Safarmashaei, D. Babazadeh, and B. Mikailpourardabili, "The effect of saffron orally administration on spermatogenesis index in rat," Advances in Environmental Biology, vol. 5, pp. 1514-1521, 2011.

[231] F. Muosa, K. AL-Rekabi, S. Askar, and E. Yousif, "Evaluation of the toxic effect of ethanolic extract of saffron in male mice after subchronic exposure. Donnish," The Journal of Pharmacy and Pharmacology, vol. 1, pp. 1-7, 2015.

[232] M. H. Modaghegh, M. Shahabian, H. A. Esmaeili, O. Rajbai, and H. Hosseinzadeh, "Safety evaluation of saffron (Crocus sativus) tablets in healthy volunteers," Phytomedicine, vol. 15, pp. 1032-1037, 2008.

[233] H. Hosseinzadeh, A. Abootorabi, and H. R. Sadeghnia, "Protective effect of Crocus sativus stigma extract and crocin (trans-crocin 4) on methyl methanesulfonate-induced DNA damage in mice organs," DNA and Cell Biology, vol. 27, pp. 657-664, 2008.

[234] M. Schmidt, G. Betti, and A. Hensel, "Saffron in phytotherapy: pharmacology and clinical uses," Wiener Medizinische Wochenschrift, vol. 2007, no. 157, pp. 315-319, 1946.

[235] J. P. Melnyk, S. Wang, and M. F. Marcone, "Chemical and biological properties of the world's most expensive spice: saffron," Food Research International, vol. 43, pp. 1981-1989, 2010.

[236] M. Bahmani, M. Rafieian, A. Baradaran, S. Rafieian, and M. Rafieian-Kopaei, "Nephrotoxicity and hepatotoxicity evaluation of Crocus sativus stigmas in neonates of nursing mice," Journal of Nephropathology, vol. 3, pp. 81-85, 2014.

[237] B. Amin, H. M. Feriz, A. T. Hariri, N. T. Meybodi, and H. Hosseinzadeh, "Protective effects of the aqueous extract of Crocus sativus against ethylene glycol induced nephrolithiasis in rats," EXCLI Journal, vol. 14, pp. 411-422, 2015.

[238] A. T. Hariri, S. A. Moallem, M. Mahmoudi, B. Memar, B. M. Razavi, and H. Hosseinzadeh, "Effect of Crocus sativus L. stigma (saffron) against subacute effect of diazinon: histopathological, hematological, biochemical and genotoxicity evaluations in rats," Journal of Pharmacopuncture, vol. 21, pp. 61-69, 2018.

[239] F. Zeynali, M. Dashti, M. Anvari, S. Hosseini, and S. Miresmaeili, "Studying teratogenic an abortificant effects of different doses of saffron (Crocus sativus) decoction in whole gestational period and the $3 \mathrm{rd}$ trimester of gestational period in mice," International Journal of Reproductive BioMedicine, vol. 7, 2009.

[240] R. Edamula, M. Deecaraman, D. S. Kumar, H. Krishnamurthy, and M. Latha, "Prenatal developmental toxicity of Crocus sativus (saffron) in wistar rats," The International journal of pharmacology and toxicology, vol. 2, pp. 46-49, 2014.

[241] C. J. Wang, L. S. Hwang, and J. K. Lin, "Reversible hepatic black pigmentation and enzyme alteration induced by prolonged feeding of high dose of crocin dyes in rats," Proceedings of the National Science Council, Republic of China. Part B, Life Sciences, vol. 8, pp. 246-253, 1984.

[242] H. Hosseinzadeh, M. Shariaty, A. Khadem-Sameni, M. Vahabzadeh, J. Ríos, and M. Recio, "Acute and subacute toxicity of crocin, a constituent of Crocus sativus L. (saffron), in mice and rats," Pharmacology, vol. 2, pp. 943-951, 2010.

[243] F. Taheri, S. Z. Bathaie, M. Ashrafi, and E. Ghasemi, “Assessment of crocin toxicity on the rat liver," mdrsjrns, vol. 17 , pp. 67-79, 2014.

[244] S. A. Moallem, M. Afshar, L. Etemad, B. M. Razavi, and H. Hosseinzadeh, "Evaluation of teratogenic effects of crocin and safranal, active ingredients of saffron, in mice," Toxicology and Industrial Health, vol. 32, pp. 285-291, 2016.

[245] H. Hosseinzadeh, S. S. Shakib, A. K. Sameni, and E. Taghiabadi, "Acute and subacute toxicities of safranal, a constituent of saffron, in mice and rats," Clinical Biochemistry, vol. 44, no. 13, p. S122, 2011.

[246] R. Rezaee and H. Hosseinzadeh, "Safranal: from an aromatic natural product to a rewarding pharmacological agent," Iranian Journal of Basic Medical Sciences, vol. 16, pp. 12-26, 2013.

[247] B. Riahi-Zanjani, M. Balali-Mood, E. Mohammadi, H. BadieBostan, B. Memar, and G. Karimi, "Safranal as a safe compound to mice immune system," Avicenna Journal of Phytomedicine, vol. 5, pp. 441-449, 2015.

[248] H. Ayatollahi, A. O. Javan, M. Khajedaluee, M. Shahroodian, and H. Hosseinzadeh, "Effect of Crocus sativus L. (saffron) on coagulation and anticoagulation systems in healthy volunteers," Phytotherapy research: PTR, vol. 28, pp. 539-543, 2014.

[249] A. H. Mohamadpour, Z. Ayati, M. R. Parizadeh, O. Rajbai, and H. Hosseinzadeh, "Safety evaluation of crocin (a constituent of saffron) tablets in healthy volunteers," Iranian Journal of Basic Medical Sciences, vol. 16, pp. 39-46, 2013. 
[250] S. C. Nair, M. J. Salomi, B. Panikkar, and K. R. Panikkar, "Modulatory effects of Crocus sativus and Nigella sativa extracts on cisplatin-induced toxicity in mice," Journal of Ethnopharmacology, vol. 31, no. 1, pp. 75-83, 1991.

[251] L. Kharchoufa, I. A. Merrouni, A. Yamani, and M. Elachouri, "Profile on medicinal plants used by the people of North Eastern Morocco: toxicity concerns," Toxicon, vol. 154, pp. 90-113, 2018.

[252] G. Martin, E. Goh, and A. W. Neff, "Evaluation of the developmental toxicity of crocetin on Xenopus," Food and Chemical Toxicology, vol. 40, pp. 959-964, 2002.

[253] Chinese Pharmacopoeia Commission, Pharmacopoeia of the People's Republic of China, The Medicine Science and Technology Press of China, Beijing, 2015.

[254] H. Hosseinzadeh and N. B. Noraei, "Anxiolytic and hypnotic effect of Crocus sativus aqueous extract and its constituents, crocin and safranal, in mice," Phytotherapy research: PTR, vol. 23, pp. 768-774, 2009.

[255] G. Georgiadou, V. Grivas, P. A. Tarantilis, and N. Pitsikas, "Crocins, the active constituents of Crocus sativus L., counteracted ketamine-induced behavioural deficits in rats," Psychopharmacology, vol. 231, pp. 717-726, 2014.

[256] K. Bajbouj, J. Schulze-Luehrmann, S. Diermeier, A. Amin, and R. Schneider-Stock, "The anticancer effect of saffron in two p53 isogenic colorectal cancer cell lines," BMC Complementary and Alternative Medicine, vol. 12, p. 69, 2012.

[257] European Directorate for the Quality of Medicines and Healthcare, European Pharmacopoeia, European Directorate for the Quality of Medicines and HealthCare, Strasbourg, 8th edition, 2014.

[258] Medicines \& Healthcare Products Regulatory Agency, British Pharmacopoeia, The Stationery Office, London, 2013.

[259] The Editorial Committee of the Japanese Pharmacopoeia, Japanese Pharmacopoeia, Ministry of Welfare, Tokyo, 2011.

[260] N. Moratalla-López, M. J. Bagur, C. Lorenzo, M. E. M.-N. R. Salinas, and G. L. Alonso, "Bioactivity and bioavailability of the major metabolites of Crocus sativus L. flower," Molecules, vol. 24, p. 2827, 2019.

[261] M. Martinez-Tome, A. M. Jimenez, S. Ruggieri, N. Frega, R. Strabbioli, and M. A. Murcia, "Antioxidant properties of Mediterranean spices compared with common food additives," Journal of Food Protection, vol. 64, pp. 1412-1419, 2001.

[262] T. H. Tseng, C. Y. Chu, J. M. Huang, S. J. Shiow, and C. J. Wang, "Crocetin protects against oxidative damage in rat primary hepatocytes," Cancer Letters, vol. 97, pp. 61-67, 1995.

[263] M. Sebastin Santhosh, M. Hemshekhar, R. M. Thushara, S. Devaraja, K. Kemparaju, and K. S. Girish, "Vipera russelli venom-induced oxidative stress and hematological alterations: amelioration by crocin a dietary colorant," Cell Biochemistry and Function, vol. 31, pp. 41-50, 2013.

[264] F. I. Abdullaev and J. J. Espinosa-Aguirre, "Biomedical properties of saffron and its potential use in cancer therapy and chemoprevention trials," Cancer Detection and Prevention, vol. 28, pp. 426-432, 2004.

[265] R. Yang, X. Tan, A. M. Thomas et al., "Crocetin inhibits mRNA expression for tumor necrosis factor-alpha, interleukin-1beta, and inducible nitric oxide synthase in hemorrhagic shock," JPEN Journal of Parenteral and Enteral Nutrition, vol. 30, no. 4, pp. 297-301, 2006.
[266] S. Kianbakht and K. Mozaffari, "Effects of saffron and its active constituents, crocin and safranal, on prevention of indomethacin induced gastric ulcers in diabetic and nondiabetic rats," Journal of Medicinal Plants Research, vol. 8, pp. 30-38, 2009.

[267] X. C. Shen and Z. Y. Qian, "Effects of crocetin on antioxidant enzymatic activities in cardiac hypertrophy induced by norepinephrine in rats," Die Pharmazie, vol. 61, pp. 348-352, 2006.

[268] L. Ferrara, D. Naviglio, and M. Gallo, "Extraction of bioactive compounds of saffron (Crocus sativus L.) by ultrasound assisted extraction (UAE) and by rapid solid-liquid dynamic extraction (RSLDE)," European Scientific Journal, ESJ, vol. 10, 2014

[269] I. Cosano, C. Pintado, A. Acevedo et al., "Microbiological quality of saffron from the main producer countries," Journal of Food Protection, vol. 72, pp. 2217-2220, 2009.

[270] C. Pintado, A. de Miguel, O. Acevedo, L. Nozal, J. L. Novella, and R. Rotger, "Bactericidal effect of saffron (Crocus sativus L.) on salmonella enterica during storage," Food Control, vol. 22, pp. 638-642, 2011.

[271] M. Abbasvali, A. Ranaei, S. S. Shekarforoush, and H. Moshtaghi, "The effects of aqueous and alcoholic saffron (Crocus sativus) tepal extracts on quality and shelf-life of Pacific white shrimp (Litopeneous vannamei) during iced storage," Journal of Food Quality, vol. 39, 742 pages, 2016.

[272] A. Aktypis, E. D. Christodoulou, E. Manolopoulou, A. Georgala, D. Daferera, and M. Polysiou, "Fresh ovine cheese supplemented with saffron (Crocus sativus L.): impact on microbiological, physicochemical, antioxidant, color and sensory characteristics during storage," Small Ruminant Research, vol. 167, pp. 32-38, 2018. 